\title{
Pathways to Persistence: Female Offending from 14 to 25
}

\author{
Elizabeth Cauffman $^{1} \cdot$ Kathryn C. Monahan $^{2}$. \\ April Gile Thomas ${ }^{1}$
}

Received: 12 May 2015 / Revised: 20 August 2015 / Accepted: 24 August 2015/

Published online: 7 September 2015

(C) Springer International Publishing AG 2015

\begin{abstract}
Purpose While violent crime among females has nearly doubled, research on crime still tends to focus on male offending. To better understand the developmental patterns of female crime, this study identifies the trajectories of female offending from ages 14-25 years and examines the risk factors for persistent offending. Female trajectories and risk factors for offending are compared to those from a matched sample of males.

Methods Participants include 172 serious (largely felony level) offending females and a matched sample of 172 males from the Pathways to Desistance study. Group-based trajectory modeling was used to identify patterns of female and male offending behavior (assessed via self-report) across 7 years.

Results Findings indicate that there is great heterogeneity in criminal behavior among serious female offenders with roughly $7 \%$ of females' criminal careers persisting into adulthood. Notable differences in the risk factors for male and female offending trajectories were found. Females who persist in their criminal careers tend to be exposed to more violence in their lives, have more mental health problems, and experience more adversarial interpersonal relationships compared to those who desist.

Conclusion Although the pathways of male and female offending may follow remarkably similar patterns, the underlying factors that distinguish among these trajectories are often different for females than for males. As such, there is great need for a more nuanced understanding of the most common precursors to persistent female offending.
\end{abstract}

Keywords Female $\cdot$ Antisocial behavior · Desistance

The age-crime curve indicates that criminal behavior typically increases during adolescence, peaks in late adolescence to young adulthood, and is followed by desistance from crime

Elizabeth Cauffman

cauffman@uci.edu

1 University of California, Irvine, Irvine, CA, USA

2 University of Pittsburgh, Pittsburgh, PA, USA 
across adulthood $[27,53,65]$. Although the age crime curve describes the pattern of crime on average in the population, individual differences in this pattern exist, with some individuals peaking in criminal behavior earlier, some individuals ceasing criminal behavior earlier, and some individuals continuing to engage in crime well into adulthood. Over the past 20 years, advanced statistical methods such as developmental trajectory analyses have been fruitful in identifying and testing theoretical predictions about such factors as when an individual's offending behavior began (onset), how long it lasts (duration), and when it ends (desistence). Predominantly, the studies that have developed these ideas about the longitudinal patterns of crime have relied on samples of males. However, more recent studies have begun to examine offending patterns among females [1, 3, 12, 19, 22, 29]. These studies largely agree that female crime, like male crime, looks remarkably heterogeneousdisplaying variable patterns of offending across the life course [17]. Importantly, these distinct patterns of offending have been associated with different outcomes during adulthood. Individuals who exhibit chronic or persistent offending, for example, tend to experience worse mental health, physical health, and economic problems than those on other trajectories [51].

Because membership in certain trajectory groups (i.e., persisting or chronic offending) is associated with more problematic outcomes than others (i.e., desisting), it is important to examine the factors that place one at risk for these more negative life paths. Yet, due to the lower prevalence of female delinquents in the population compared to male delinquents [55] and the tendency for studies of criminal behavior to focus on males, our understanding of the factors that influence females' trajectories of offending is relatively narrow. Small sample size and few serious offending females have been a shortcoming of many studies of female offending [17]. Furthermore, many trajectory studies have been limited by participant age, in which delinquency patterns of certain subgroups are only examined through middle adolescence $[36,51]$. Traditionally, most studies that assess trajectories of crime begin with participants who have engaged in low-level antisocial behavior and follow them across development. As a result, these studies end up with only a small subsample of individuals that eventually engage in high levels of crime; this is especially true for females who have lower base rates of criminal behavior.

The present study aims to address these gaps in the literature by extending beyond middle adolescence to examine trajectories of female offending into adulthood and address questions about the patterns of female crime across development. Specifically, this study will take an in-depth look at the trajectories of female offending across adolescence and into adulthood using a sample of known serious juvenile offenders. As our sample consists of only high-level offenders by design, we are uniquely poised to answer theoretical questions about the developmental patterns of serious female offending from ages 14 to 25 . Rather than focusing on the precursors of female crime, the focus of the present study is on the developmental offset-either desistance in or persistence from - serious crime among females and the risk factors (assessed during adolescence) for such trajectories.

\section{Developmental Trajectories of Criminal Behavior}

Although there are multiple life course theories of criminal behavior that emphasize heterogeneity in criminal behavior, perhaps the most widely cited and studied 
is Moffitt's [39] developmental taxonomy of antisocial behavior, which was created in an effort to explain observed heterogeneity in patterns of antisocial behavior. Moffitt's work hypothesized three distinct trajectories of antisocial behavior: a life-course persistent offending trajectory (referring to the developmental pathway of individuals who engage in chronic antisocial behavior across each stage of the lifespan), an adolescence-limited offending trajectory (referring to the pathway of those individuals who engage in antisocial behavior only during adolescence), and an abstainer trajectory (referring to the pathway of those who never engage in antisocial behavior). Later work has suggested that additional subgroups may have been unaccounted for in Moffitt's original taxonomy, such as a childhood-limited pathway (referring to antisocial behavior that occurs only during childhood) and a low-level chronic antisocial behavior pathway (referring to consistently low-level antisocial behavior that continues across development) (reviewed by [41]). A review by Piquero [54] of nine trajectory studies that met criteria for inclusion (that is, studies that used offender samples and continued data collection until participants were adults) at the time of publication revealed that between four to six trajectories were consistently shown across the various studies. While there may be more distinct pathways than Moffitt suggested, evidence suggests that for most youthful offenders, criminal behavior ceases as they transition from adolescence to adulthood. For a small minority of youth, this offending behavior persists into adulthood.

A core foundation of this taxonomy is that the precursors of offending behavior may vary by subgroup. Specifically, those who engage in antisocial behavior that is limited to adolescence are thought to reflect a more normative pattern of offending that at its essence is a result of "social mimicry" ([39], p. 686) or modeling the behavior of antisocial peers. However, the notion that adolescence-limited antisocial behavior is normative has recently been challenged $[57,58]$. On the other hand, life-course persistent offenders are theorized to develop an antisocial personality due to interactions over time between their own difficult temperament and negative environmental responses. Although the original taxonomy initially examined the trajectories of antisocial behavior for males only, Moffitt [40] has suggested that the taxonomy should apply equally well to females. Later analyses by Moffitt and colleagues [42] suggested that although the patterns of the adolescence limited pathway were similar for both genders, the life-course persistent offending trajectory was relatively nonexistent among females, with only $1 \%$ of the female sample fitting this trajectory. However, some highlight the fact that chronic offenders make up only $5 \%$ of offenders and argue that the lack of findings for a persistent female offending group may be due to the low base rate of these individuals in the population [20]. Despite the almost nonexistent life-course persistent group found in the earlier Moffitt [42] study, a follow-up analysis of the same sample documented evidence of a larger subgroup of persistent female offenders [51], as have numerous other studies [1, 3, 10, 11, $34,61,73]$. However, it is important to note that the definition of "persistence" varied considerably between studies. Research suggests that this trajectory group consists of relatively small proportions of females and that, in general, there tend to be more persistent offending males than females [17]. Importantly, both males and females on this pathway of persistent offending are more likely to experience problems in adulthood [3, 38, 51]. 


\section{Predictors of Female Persistence}

Prior studies have tended to focus on what leads individuals to engage in crime; less is known about which factors lead individuals (and more specifically, females) to persist in or desist from offending. Although longitudinal studies of female offending are on the rise, the number of studies examining risk factors for persistent offending remains limited as several of the existing trajectory studies either did not examine predictors of offending pathways or did not include a group representative of persistent female offenders. Highlights from these studies have important implications for the present study, and we review them in turn.

In a retrospective study of 131 female inmates, Gunnison and McCartan [22] noted differences between females classified as late onsetters and those classified as persisters. Specifically, persisters were more likely than late onsetters to have had a head injury, been a gang member, have friends who had been arrested, experienced sexual abuse, experienced physical abuse, been diagnosed with depression, and consumed drugs or alcohol as a juvenile [22]. Among a non-offender sample of Puerto Rican youth aged 5 to 13 years living in the Bronx, NY, four distinct trajectory groups were found among females (non-offenders, low-offending desisters, high-offending desisters, and highoffending persisters) [29]. In comparing the persistent offending females to the nonoffending females, some notable differences emerged. Persistent offending girls were found to report more positive attitudes toward delinquency, greater sensation seeking, and were more likely to report being exposed to violence than non-offending girls [29]. A third study assessed differences among females who persist in offending (measured as self-reported arrest) from those who desist from offending across the observation period [70]. Within this sample of 340 women, those who were currently employed and attending school were more likely to exhibit desistence from crime. Persistence in offending, on the other hand, was more common among white women, those who were currently using illegal drugs and those with a prior history of crime [70].

In summary, predictors of persistent offending have been identified in several domains. One factor in particular appeared as a consistent predictor of persistence in multiple studies - exposure to violence or abuse. This is unsurprising given that exposure to traumatic events, such as victimization or witnessing violence, has been consistently associated with delinquency $[32,60]$. Evidence from a number of studies has demonstrated gender differences in exposure to trauma, with many suggesting that girls have been exposed to more adverse events than boys (although findings have been mixed) (see review by [32]). Furthermore, findings indicate that there may be gender differences in the types of trauma experienced by youth. For example, girls are more likely than boys to report that they were the direct victims of trauma, whereas boys were more likely to report witnessing violence $[6,31]$. Additionally, girls are more likely to experience trauma involving sexual abuse or rape than boys [24]. Therefore, exposure to violence appears to be an important factor to consider when examining predictors of offending trajectories among females.

\section{The Present Study}

Numerous factors have been suggested to predict female offending patterns, yet prior studies have been limited in several ways (as discussed by [17]). Many earlier 
examinations of female offending trajectories have relied on official reports of crime data, which can be problematic in that such reports only account for offenses that have been caught by law enforcement, and as a consequence, they often underreport an individual's true level of engagement in criminal behavior. The present study addresses this limitation by utilizing self-reports of engagement in offending behavior, which have been shown to be more complete characterizations of offending [66, 67]. Further, prior studies have largely relied on normative or low-level offending samples. Because persistent offenders by nature tend to be more serious offenders, these samples often have too few individuals who meet this classification of offending. As the purpose of the present study is to better understand the persistent female offender, we specifically utilize a sample of females who have been convicted of a felony or similarly serious offense.

This study aims to clarify our understanding of the developmental patterns of female crime by examining trajectories of female offending from ages 14 to 25 . Specifically, we aim to address four main questions. First, what do the trajectories of female offending look like and are we able to identify persistent female offenders? Second, how do these trajectories of female offending compare to similar male offenders? Third, what are the risk factors for persistent female offending? Specifically, how do risk factors in demographic, cognitive, mental health, psychological, community, and interpersonal domains contribute to offending trajectories among females? Finally, because there are preexisting differences between males and females who end up in the justice system, we test whether these same risk factors are related to a matched sample of male offenders. This allows a comparison of how risk factors for offending trajectories differ between female and male offenders, after accounting for such preexisting differences. In doing so, we conduct the first parallel analysis of the predictors of offending trajectories of female and male serious offenders from adolescence through adulthood.

\section{Method}

\section{Participants}

Participants were females and a matched sample of males enrolled in the Pathways to Desistance study (see [47]), a longitudinal study of serious juvenile offenders in Phoenix and Philadelphia (see [59] for complete details of study methodology). Adolescents were eligible for study participation if they were between 14 and 17 years of age at the time of their adjudication and if their crimes included felony offenses (against persons and property), certain misdemeanor, weapon offenses, or sexual assault (felony drug crimes were capped at $15 \%$ for the male sample). Of eligible youth identified, $67 \%$ of those whom we located and invited to participate agreed to enroll in the study. Compared with youth who declined to participate in the study, enrolled participants had more prior arrests leading to formal charges (2.1 vs. 1.5 for nonparticipants), were somewhat younger at first arrest (13.9 vs. 14.2 years for nonparticipants), were somewhat younger at adjudication (15.9 vs. 16.1 years for nonparticipants), and were more likely to be non-Hispanic Caucasian (25 vs. $20 \%$ for nonparticipants). Although these differences are statistically significant, the magnitude of differences is modest. The total sample consists of both males and females $(N=$ 184 females; $N=1170$ males). 
The present study focuses only on the female sample for the Pathways study and a matched sample of males. The present analyses include all females who had valid data for at least $70 \%$ of the assessments $(N=178)$. This same strategy was used to identify a sample to study trajectories of offending among males in the Pathways sample (Monahan, Steinberg, Cauffman, and Mulvey, in press; [44, 46]). The females who had valid data for $70 \%$ of assessments are no different in age $(t(182)=0.026, p=0.98)$, number of prior petitions $(t(182)=-0.37, p=0.71)$, study site location $\left(\chi^{2}(1)=2.49 ; p=\right.$ $0.11)$, or race or ethnicity $\left(\chi^{2}(3)=4.72 ; p=0.19\right)$ to the 6 females who provided less data and were excluded from analyses.

We matched a male sample to the female sample based on race, age, and committing offense using nearest-neighbor matching without replacement. The resulting sample consisted of 172 males who were matched with 172 females (6 females did not have a match). One male was found to have lied about his age and was thus excluded from the analyses, leaving a total sample of 171 males. There were no significant differences between the matched and unmatched females in age $(t(182)=1.60, p=0.12)$, number of arrests $(t(182)=-0.65, p=0.52)$, or study site $\left(\chi^{2}(1)=0.23 ; p=0.63\right)$. Compared to females who were matched, females who were not matched were more likely to be "other" race or ethnicity $\left(\chi^{2}(3)=8.63 ; p=0.04\right)$ - this is unsurprising given that there are few individuals in the overall sample who identified as "other" and thus a relatively small pool of males from which to draw for matches. Comparing matched and unmatched males, there were no differences in age $(t(1168)=1.16, p=0.25)$, number of arrests $(t(1166)=-1.24, p=0.22)$, or study site $\left(\chi^{2}(1)=0.32 ; p=0.57\right)$. Unmatched males were more likely to be White and less likely to be Black $\left(\chi^{2}(3)=7.80 ; p=0.05\right)$.

The baseline interview was conducted an average of 36.9 days $(\mathrm{SD}=20.6)$ after the youths' adjudication (for those adolescents in the juvenile system), or if participants were eligible for prosecution as an adult, their decertification (i.e., waiver) hearing in Philadelphia or their adult arraignment in Phoenix. At the time of the baseline interview, participants were predominantly of lower socioeconomic status (e.g., less than $4.5 \%$ of the youths' parents held a 4-year college degree, and $40 \%$ of the youths' parents had less than a high school education) and were ethnically diverse with $41 \%$ African American, $35 \%$ Hispanic American, $20 \%$ non-Hispanic Caucasian, and $4 \%$ other.

\section{Procedures}

The juvenile court in each site provided the names of eligible adolescents based on age and offenses. Interviewers attempted to contact each eligible juvenile and his or her parent or guardian to obtain juvenile assent and parental consent. Once consents had been obtained, interviews were conducted in a facility (if the participant was confined), in the home, or in an agreed-upon location in the community.

The baseline interview was administered over 2 days in two 2-hour sessions. Interviewers and participants sat side-by-side facing a computer, and questions were read aloud to avoid comprehension or reading difficulties. Participants were informed that the research team had an affirmative obligation to maintain confidentiality from the federal government, which prohibited our disclosing any information obtained during the study to anyone outside the study. Youths were informed that the only exceptions to a promise of confidentiality were (a) if child abuse was suspected or (b) if the participant expressed plans to hurt himself or someone else, (c) had a specific plan to commit a 
crime in the future, or (d) disclosed that someone was in jail for a crime that the participant had committed. Interviews were conducted out of earshot of other individuals whenever possible. All recruitment and assessment procedures were approved by the institutional review boards of the participating universities. Adolescents were paid $\$ 50$ for their participation in the baseline interview (when allowed by facility rules).

Participants were reinterviewed every 6 months for the 3 years following the baseline interview; after 36 months, participants were interviewed annually for the remaining 4 years of the study. Each of the follow-up interviews was completed in one 2-hour session. Participant compensation for the follow-up interviews increased gradually over time to a maximum of $\$ 150$ in order to minimize attrition. Retention of the sample was excellent. From the baseline interview to the 84-month follow-up, the analytic sample of 178 females, 134 females (75.3\%) completed all 11 interviews; 30 females $(16.9 \%)$ completed ten interviews; 6 individuals $(3.4 \%)$ completed nine interviews; 6 individuals (3.4\%) completed eight interviews, and 2 individuals $(1.1 \%)$ completed seven interviews. Retention of the 171 matched male sample was also excellent: 107 males (62.6\%) completed all 11 interviews; 31 males $(18.1 \%)$ completed 10 interviews; 12 individuals (7\%) completed nine interviews; 8 individuals (4.7\%) completed eight interviews, and 3 individuals $(1.8 \%)$ completed seven interviews, and only nine males completed fewer than seven interviews.

\section{Measures}

Variables of interest for the present study were self-reported measures of antisocial behavior and time spent incarcerated (exposure time) as well as risk factors for persistent offending. Given the extensive number of risk factors, those measures are presented in Table 1. Also, for a detailed description of each measure as well as the individual items, we refer the reader to the Pathways to Desistance website: http://www.pathwaysstudy.pitt.edu/.

Antisocial Behavior Involvement in antisocial behavior was assessed with a revised version of the Self-Report of Offending [28]. Participants reported if they had been involved in any of 22 different aggressive or income-generating antisocial acts (e.g., "Taken something from another person by force, using a weapon," "Carrying a weapon," "Stolen a car or motorcycle to keep or sell," "Used checks or credit cards illegally"). At the baseline and 48through 84-month annual interviews, these questions were asked with the qualifying phrase, "in the past 12 months have you..." At the 6- through 36-month bi-annual interviews, these questions were asked with the qualifying phrase, "In the past 6 months, have you..."

Variety scores, a count of the number of different types of antisocial acts that an individual endorsed, were calculated for each annual interval. Variety scores are widely used in criminological research because they are highly correlated with measures of seriousness of antisocial behavior yet are less prone to recall errors than self-reported frequency scores, especially when the antisocial act is committed frequently, such as selling drugs. Some have argued that variety scores and frequency scores represent the same propensity to engage in antisocial behavior, and given the problems associated with frequency scores, variety scores represent a preferred method of measuring antisocial behavior, particularly in a sample with high rates of antisocial behavior $[26,66]$. In the computation of variety scores, each specific offense (e.g., "Carrying a weapon") was counted only once in any yearlong recall period, even if an individual endorsed the 
Table 1 Measures administered to assess risk factors for antisocial behavior

\begin{tabular}{|c|c|c|c|}
\hline Risk factors & Measure & Description & Reference \\
\hline \multicolumn{4}{|l|}{ Demographic factors } \\
\hline Age & & $\begin{array}{l}\text { Self-reported birth date at the } \\
\text { baseline interview }\end{array}$ & $\begin{array}{l}\text { Created for this } \\
\text { study }\end{array}$ \\
\hline Race & & $\begin{array}{l}\text { Based on youth self-report and or } \\
\text { ganized into four categories: } \\
\text { White, Black, Latino, or } \\
\text { Other race }\end{array}$ & $\begin{array}{l}\text { Created for this } \\
\text { study }\end{array}$ \\
\hline $\begin{array}{l}\text { Parent } \\
\text { deviance }\end{array}$ & & $\begin{array}{l}\text { Assessed as a composite of youth } \\
\text { self-reported mother arrest his } \\
\text { tory (ever arrested: yes or no), } \\
\text { father arrest history (ever } \\
\text { arrested: yes or no), mother } \\
\text { substance use disorder history } \\
\text { (ever had substance use } \\
\text { disorder: yes or no), and father } \\
\text { substance use disorder history } \\
\text { (ever had substance use } \\
\text { disorder: yes or no) }\end{array}$ & $\begin{array}{l}\text { Created for this } \\
\text { study }\end{array}$ \\
\hline Prior criminal behavior & & $\begin{array}{l}\text { Obtained via official records, this } \\
\text { was a composite of age at first } \\
\text { arrest and number of petitions } \\
\text { prior to the baseline interview }\end{array}$ & $\begin{array}{l}\text { Obtained from } \\
\text { official records }\end{array}$ \\
\hline \multicolumn{4}{|l|}{ Cognitive functioning } \\
\hline IQ & $\begin{array}{l}\text { Wechsler Abbreviated } \\
\text { Scale of Intelligence } \\
\text { (WASI) }\end{array}$ & $\begin{array}{l}\text { Using the vocabulary (42 items) } \\
\text { and matrix reasoning ( } 35 \text { items) } \\
\text { tasks, the WASI is a quick } \\
\text { estimate of an individual's level } \\
\text { of intellectual functioning, with } \\
\text { higher scores indicating greater } \\
\text { intellectual ability }\end{array}$ & {$[71]$} \\
\hline $\begin{array}{l}\text { Neurological } \\
\text { functioning }\end{array}$ & $\begin{array}{l}\text { Trail-making test } \\
\text { (part B only) }\end{array}$ & $\begin{array}{l}\text { Part B measures three types of } \\
\text { cognitive functioning: ability to } \\
\text { sequence, ability to shift } \\
\text { cognitive set, and processing } \\
\text { speed. Longer completion times } \\
\text { (child: part B, greater than } 37 \mathrm{~s} \text {; } \\
\text { adult: part B, greater than } 85 \mathrm{~s} \text { ) } \\
\text { are indicative of neurological } \\
\text { deficit }\end{array}$ & {$[56]$} \\
\hline \multicolumn{4}{|l|}{ Mental health } \\
\hline $\begin{array}{l}\text { Lifetime } \\
\text { history of } \\
\text { substance } \\
\text { use disorder }\end{array}$ & $\begin{array}{l}\text { Composite International } \\
\text { Diagnostic } \\
\text { Interview (CIDI) }\end{array}$ & $\begin{array}{l}\text { Diagnoses were based on youth } \\
\text { completion of a structured } \\
\text { diagnostic interview. Substance } \\
\text { use diagnosis was assessed as } \\
\text { whether or not individuals had } \\
\text { ever met threshold for a } \\
\text { substance use disorder } \\
\text { (drug or alcohol) }\end{array}$ & $\begin{array}{l}\text { World Health } \\
\text { Organization, } \\
1990\end{array}$ \\
\hline $\begin{array}{l}\text { Lifetime } \\
\text { history of } \\
\text { mental health } \\
\text { disorder }\end{array}$ & $\begin{array}{l}\text { Composite International } \\
\text { Diagnostic } \\
\text { Interview (CIDI) }\end{array}$ & $\begin{array}{l}\text { Diagnoses were based on youth } \\
\text { completion of a structured } \\
\text { diagnostic interview. Mental } \\
\text { health disorder was a composite } \\
\text { of whether the youth had ever } \\
\text { reached the threshold of a } \\
\text { disorder of major depression, }\end{array}$ & $\begin{array}{l}\text { World Health } \\
\text { Organization, } \\
1990\end{array}$ \\
\hline
\end{tabular}


Table 1 (continued)

\begin{tabular}{|c|c|c|c|}
\hline Risk factors & Measure & Description & Reference \\
\hline & & $\begin{array}{l}\text { dysthymia, mania, or } \\
\text { posttraumatic stress disorder }\end{array}$ & \\
\hline \multicolumn{4}{|c|}{ Psychological risk factors } \\
\hline Psychopathy & $\begin{array}{l}\text { Psychopathy } \\
\text { checklist-youth } \\
\text { version (PCL:YV) }\end{array}$ & $\begin{array}{l}\text { Following an interview with the } \\
\text { participant as well as a review } \\
\text { of institutional records and } \\
\text { parent reports, the interviewer } \\
\text { used a three-point ordinal scale } \\
\text { to indicate how well each of the } \\
20 \text { items on the PCL:YV } \\
\text { applied. Higher PCL:YV scores } \\
\text { indicate more psychopathic } \\
\text { characteristics }\end{array}$ & {$[18]$} \\
\hline Legal cynicism & $\begin{array}{l}\text { Procedural justice } \\
\text { inventory }\end{array}$ & $\begin{array}{l}\text { Legal cynicism ( } 5 \text { items) reflects } \\
\text { the extent to which a youth } \\
\text { holds values with the laws and } \\
\text { norms of society against the } \\
\text { legal system of police (e.g., } \\
\text { "Laws are meant to be } \\
\text { broken."). Higher values } \\
\text { indicate norms favorable to } \\
\text { breaking the law }\end{array}$ & {$[69]$} \\
\hline Legitimacy & $\begin{array}{l}\text { Procedural justice } \\
\text { inventory }\end{array}$ & $\begin{array}{l}\text { Legitimacy ( } 11 \text { items) reflects the } \\
\text { extent to which individuals hold } \\
\text { values that are supportive of } \\
\text { police (e.g., "I feel people } \\
\text { should support the police.") }\end{array}$ & {$[69]$} \\
\hline $\begin{array}{l}\text { Moral } \\
\text { disengagement }\end{array}$ & $\begin{array}{l}\text { Mechanisms of moral } \\
\text { disengagement }\end{array}$ & $\begin{array}{l}\text { Assesses an adolescent's attitudes } \\
\text { concerning the treatment of } \\
\text { others. Youth respond to } 32 \\
\text { items (e.g., "It is alright to beat } \\
\text { someone who bad mouths your } \\
\text { family.") on a 3-point Likert } \\
\text { scale ranging from "disagree" to } \\
\text { "agree," with higher scores in } \\
\text { dicating a greater moral } \\
\text { detachment }\end{array}$ & $\begin{array}{l}\text { Bandura, } \\
\text { Barbarnelli, } \\
\text { Caprara, and } \\
\text { Pastorelli, } 1996\end{array}$ \\
\hline $\begin{array}{l}\text { Psychosocial } \\
\text { maturity }\end{array}$ & $\begin{array}{l}\text { Weinberger Adjustment } \\
\text { Inventory (WAI); Future } \\
\text { Outlook Inventory (FOI); } \\
\text { The Psychosocial Maturity } \\
\text { Inventory (PSMI); } \\
\text { resistance to peer } \\
\text { influence (RPI) }\end{array}$ & $\begin{array}{l}\text { Temperance, perspective, } \\
\text { and responsibility are } \\
\text { conceptualized as indicating } \\
\text { psychosocial maturity [62]. } \\
\text { Each of these three constructs is } \\
\text { assessed by two measures (total } \\
\text { of } 6 \text { measures combined). These } \\
\text { six measures are standardized } \\
\text { and then combined to create a } \\
\text { maturity score with higher } \\
\text { scores indicative of more } \\
\text { mature behavior. } \\
\text { Temperance=Impulse control and } \\
\text { suppression of aggression } \\
\text { subscales of the WAI } \\
\text { Perspective=Consideration of } \\
\text { others subscale of WAI and } \\
\text { Future Outlook Inventory }\end{array}$ & $\begin{array}{l}\text { WAI: Weinberger, } \\
\text { Tublin, Ford, } \\
\text { and Feldman, } \\
1990 \\
\text { FOI: Scheier and } \\
\text { Carver, 1985 } \\
\text { FOI: Zimbardo, } \\
\text { 1990 } \\
\text { FOI: Strathman, } \\
\text { Gleicher, } \\
\text { Boninger, and } \\
\text { Edwards, 1994 } \\
\text { PSMI: Greenberger } \\
\text { et al., 1974 } \\
\text { RPI: [63] }\end{array}$ \\
\hline
\end{tabular}


Table 1 (continued)

\begin{tabular}{|c|c|c|c|}
\hline Risk factors & Measure & Description & Reference \\
\hline & & $\begin{array}{l}\text { Responsibility }=\text { Psychosocial } \\
\text { Maturity Inventory and } \\
\text { resistance to peer influence }\end{array}$ & \\
\hline \multicolumn{4}{|c|}{ Contextual and interpersonal risk factors } \\
\hline $\begin{array}{l}\text { Neighborhood } \\
\text { disadvantage }\end{array}$ & $\begin{array}{l}\text { Neighborhood } \\
\text { conditions measure }\end{array}$ & $\begin{array}{l}\text { Assesses the physical disorder of a } \\
\text { neighborhood (e.g., "cigarettes } \\
\text { on the street or in the gutters," } \\
\text { "graffiti or tags"), as well as } \\
\text { social disorder (e.g., "adults } \\
\text { fighting or arguing loudly," } \\
\text { "people using needles or } \\
\text { syringes to take drugs") with } \\
\text { higher scores indicating a } \\
\text { greater degree of disorder } \\
\text { within the community } \\
\text { (21 items) }\end{array}$ & $\begin{array}{l}\text { Sampson and } \\
\text { Raudenbush, } \\
1999\end{array}$ \\
\hline $\begin{array}{l}\text { Parental } \\
\text { knowledge }\end{array}$ & $\begin{array}{l}\text { Parental monitoring } \\
\text { inventory }\end{array}$ & $\begin{array}{l}\text { Assesses youths' perspectives of } \\
\text { parental knowledge (e.g., How } \\
\text { much does X know about how } \\
\text { you spend your free time) on } 9 \\
\text { items that are answered on a 4- } \\
\text { point Likert scale ranging from } \\
\text { "doesn't know at all to "knows } \\
\text { everything”. Even if a youth } \\
\text { does not live with their primary } \\
\text { caretaker, they are asked these } \\
\text { questions. If the youth lives } \\
\text { with the primary caretaker, four } \\
\text { additional items are asked to } \\
\text { assess parental monitoring of } \\
\text { the youth's behavior (e.g., } \\
\text { "How often do you have a set } \\
\text { time to be home on weekend } \\
\text { nights?") }\end{array}$ & {$[64]$} \\
\hline $\begin{array}{l}\text { Maternal } \\
\text { hostility }\end{array}$ & $\begin{array}{l}\text { Quality of parental } \\
\text { relationships inventory }\end{array}$ & $\begin{array}{l}\text { Maternal hostility (e.g., "How } \\
\text { often does your mother get } \\
\text { angry at you?") was assessed } \\
\text { via a 9-item measure where } \\
\text { participants respond on a 4- } \\
\text { point Likert scale ranging from } \\
\text { "always" to "never," with } \\
\text { higher scores indicating a more } \\
\text { harsh parenting style }\end{array}$ & {$[9]$} \\
\hline $\begin{array}{l}\text { Peer } \\
\text { delinquency }\end{array}$ & $\begin{array}{l}\text { Delinquent behavior } \\
\text { scale }\end{array}$ & $\begin{array}{l}\text { Four peer measures (peer } \\
\text { antisocial behavior, peer } \\
\text { antisocial influence, proportion } \\
\text { of friends arrested, and } \\
\text { proportion of friends jailed) } \\
\text { were used to create a peer } \\
\text { delinquency scale. Peer } \\
\text { delinquency ( } 12 \text { items) is the } \\
\text { number of adolescent's friends } \\
\text { who engage in delinquent } \\
\text { behaviors. Peer antisocial } \\
\text { influence ( } 9 \text { items) is the extent } \\
\text { to which peers influence an } \\
\text { adolescent to engage in }\end{array}$ & {$[68]$} \\
\hline
\end{tabular}


Table 1 (continued)

\begin{tabular}{|c|c|c|c|}
\hline Risk factors & Measure & Description & Reference \\
\hline & & $\begin{array}{l}\text { delinquent behaviors. Youth } \\
\text { also nominated up to four of the } \\
\text { closets friends and then reported } \\
\text { on whether or not the friend(s) } \\
\text { had ever been arrested or jailed. } \\
\text { These four measures were } \\
\text { standardized and combined into } \\
\text { a composite score of association } \\
\text { with delinquent peers }\end{array}$ & \\
\hline $\begin{array}{l}\text { Age difference } \\
\text { in romantic } \\
\text { relationship }\end{array}$ & & $\begin{array}{l}\text { Those who were engaged in a } \\
\text { "serious romantic relationship" } \\
\text { were asked to report on the age } \\
\text { of their romantic partner. A } \\
\text { difference score was calculated } \\
\text { between the participant's age } \\
\text { and the romantic partner's age. } \\
\text { Those who did not have a } \\
\text { romantic partner were treated as } \\
\text { missing }\end{array}$ & $\begin{array}{l}\text { Created for this } \\
\text { study }\end{array}$ \\
\hline $\begin{array}{l}\text { Romantic } \\
\text { partner } \\
\text { antisocial } \\
\text { influence }\end{array}$ & $\begin{array}{l}\text { Adapted from delinquent } \\
\text { behavior scale }\end{array}$ & $\begin{array}{l}\text { Romantic partner antisocial } \\
\text { influence is the extent to which } \\
\text { the participants' romantic } \\
\text { partner influenced the } \\
\text { adolescent to engage in } \\
\text { delinquent behaviors. Those } \\
\text { who did not have a romantic } \\
\text { partner were treated as missing }\end{array}$ & Adapted from [68] \\
\hline $\begin{array}{l}\text { Exposure to } \\
\text { violence }\end{array}$ & $\begin{array}{l}\text { Exposure to violence } \\
\text { inventory }\end{array}$ & $\begin{array}{l}\text { Modified for this study to assess } \\
\text { the frequency of exposure to } \\
\text { violent events as either } \\
\text { experienced (i.e., victim- } 6 \\
\text { items) or observed (i.e., } \\
\text { witnessed-7 items) }\end{array}$ & $\begin{array}{l}\text { Selner-Ohagan, } \\
\text { Kindlon, Buka, } \\
\text { Raudenbush and } \\
\text { Earls, } 1998\end{array}$ \\
\hline
\end{tabular}

item in both 6-month intervals. Thus, we created a count of the total number of different antisocial acts that an individual endorsed across a yearlong interval.

Across time, the standard deviation (and variance) was always larger than the mean, indicating overdispersion. As such, antisocial behavior was not normally distributed and was modeled as a zero-inflated Poisson distribution in all analyses (see subsequent Plan of Analyses section). In general, antisocial behavior in the sample declined over time, but the standard deviations suggest that some individuals engaged in higher levels of offending well into their 20s.

Exposure Time Because incarceration can limit opportunity to engage in antisocial acts, failure to account for the time spent in the community, as opposed to in a secure setting, can affect the identification of trajectories of antisocial behavior [52]. Youths reported on a calendar the number of days during the recall period that they had been in a detox/drug treatment program, psychiatric hospital, residential treatment program, or secure institution. The proportion of time that an individual spent in an institutional setting during the year was calculated and used as a covariate in models. Because this information was not available at 
the baseline interview, all baseline values for this variable were set to 1, a method consistent with other work on antisocial behavior that utilizes exposure time as a covariate (e.g., [44-46]).

\section{Plan of Analyses}

Analyses were conducted in five steps. First, semi-parametric group-based modeling was used to identify trajectories of antisocial behavior by age separately for females and males. Group-based modeling is a data-driven analytic technique that organizes individuals together based on similar patterns of development on a variable over time. The entire pattern of development - from adolescence to early adulthood - is used to derive the trajectory of antisocial behavior. Second, we compared the persisting female offending trajectory to each of the other desisting trajectories using multinomial logistic regression. Third, when significant differences were detected within the multinomial logistic regression, planned contrasts were used to compare each trajectory group to the persisting female trajectory. Fourth, we used multinomial regression to compare the persisting males in the matched sample to each of the other trajectory groups. Finally, when significant differences were detected with the multinomial regression, we used planned contrasts to compare each trajectory group to the persisting male group.

With respect to identifying patterns of antisocial behavior over time, we used groupbased trajectory modeling $[48,49]$ to identify trajectories of antisocial behavior in the females and separately in the matched sample of males. Because analyses were based on count data (the number of different antisocial acts endorsed), we used zero-inflated Poisson modeling to account for the clustering at zero [33]. We simultaneously derive the probability that each individual belongs to a given group based on his or her data (i.e., posterior probabilities of group membership) and the maximum-likelihood parameter estimates associated with membership in each of the defined trajectories (i.e., average level and rate of change for a given group). On the basis of posterior probabilities, individuals are assigned membership in their most likely group trajectory. Antisocial behavior was assessed at baseline and seven annual follow-up interviews and the age range across analyses spanned from 14 to 25 years of age. Proportion of time in institutional placement, as opposed to being in the community, was used as a covariate when deriving trajectories of antisocial behavior.

Different group solutions were tested and the fit of different models was compared using the log likelihood and the Bayesian information criterion (BIC; [30]). Solutions with up to seven different groups were considered. The best trajectory solution was determined by three criteria: the lowest fit value, particularly the BIC value across models, a conceptually clear model, and a model in which each group included at least $5 \%$ of the sample. The number of latent classes was decided upon and then the form of the polynomial (e.g., linear, quadratic) was determined for each latent class. The highest significant polynomial trend was included in analyses. Posterior probabilities were estimated for the likelihood of being in each trajectory group. Posterior probabilities reflect the likelihood that an individual would belong to each of the derived groups. Ideally, each individual should have a very high probability of belonging to one group and very low probabilities of membership in all other groups. In general, posterior probabilities above .70 indicate that individuals are well matched to groups and that an adequate group solution has been achieved [48]. For ease of interpretability, we assign names to each trajectory group based on theoretical nomenclature (Persisters, Early- 
desisters, and Late-desisters). It is noteworthy that, given this is a sample of serious antisocial offenders, all individuals in the sample are either desisters or persisters. Names such as low, moderate, early-desister, or late-desister are simply relative terms to compare these youth.

Full information maximum likelihood was used to account for missing data within our analytic sample (e.g., if an individual is missing data at a given time point). The advantage of FIML is that it uses all data, regardless of the missing data pattern. Consequently, it protects against bias in analyses and is equivalent to other missing data strategies (i.e., multiple imputation; [21]).

Multinomial logistic regression was used for analyses that regressed each distinct offending trajectory (all the separate desisting categories, including persistent offenders) on risk factors for offending. When an overall difference was found between the groups on a given risk factor, subsequent planned contrasts compared each group to the persisting trajectory. Because of limited sample size, each covariate was tested separately and the Benjamini-Hochberg adjustment was used to correct for these multiple tests. The BenjaminiHochberg adjustment, also called the false discovery rate, adjusts a $p$ value for statistical tests to reflect the number of tests that were conducted, hence controlling for type I error. This family-wise adjustment is advantageous over other corrections such as the Bonferroni because it is less conservative. A $p$ value of $<.05$ was used and when a significant group difference was found after the correction, we conducted the planned contrasts test for the variable.

\section{Results}

\section{Are There Persistent Female Offenders?}

Group-based trajectory modeling [48, 49] was used to identify trajectories of antisocial behavior within the female sample. We estimated models including up to six groups. Based on the log-likelihood values, low BIC value, and criteria for model solution (see Plan of Analyses), a five-group solution was found to provide the best fit to the data (Table 2), and no group consisted of less than $5 \%$ of the sample. Moreover, the six group solutions did not provide a trajectory group that was unique in shape or function. Consequently, we selected the five group solution as the most parsimonious. Figure 1 presents the five trajectories of female offending by age. The first group (39.9\% of the sample) consisted of individuals who reported low levels of offending at every time point (low). The second group (21.9\%) showed moderate levels of offending, with gradual declines in offending in early adulthood (moderate). The third group (21.3\%) engaged in high levels of antisocial behavior in early adolescence, but declined in antisocial behavior steadily and rapidly thereafter (early-desister). The fourth group (10.1\%) engaged in high levels of antisocial behavior in mid-adolescence and then declined in antisocial behavior across the transition to adulthood (late-desister). Finally, the fifth group (6.7 \%) reported relatively high levels of antisocial behavior consistently from ages 14 to 25 (persisters). Posterior probabilities indicated that, on average, individuals were well matched to the groups to which they were assigned (average posterior probabilities were as follows: low $=.85$, moderate $=.85$, earlydesister $=.77$, late-desister $=.91$, persister $=.97$ ). Thus, female offending is not a homogeneous group of girls but rather much more heterogeneous with nearly $7 \%$ of female offenders continuing to pursue criminal careers from adolescence into adulthood. 
Table 2 Bayesian information criterion (BIC) and $2 \log _{\mathrm{e}}\left(B_{10}\right)$ of the group-based trajectory models considered

\begin{tabular}{clll}
\hline No. of groups & BIC & Null model & $2 \log _{\mathrm{e}}\left(B_{10}\right)$ \\
\hline Females only & & & \\
1 & -2389.89 & - & - \\
2 & -2021.08 & 1 & 737.62 \\
3 & -1970.11 & 2 & 101.94 \\
4 & -1951.82 & 3 & 36.58 \\
5 & -1932.82 & 4 & 38 \\
6 & -1932.63 & 5 & 0.38 \\
7 & -1939.05 & 6 & -12.84 \\
Males only & & & \\
1 & -3115.78 & - & - \\
2 & -2610.94 & 1 & 504.84 \\
3 & -2487.58 & 2 & 22.08 \\
4 & -2465.50 & 3 & 8.08 \\
5 & -2457.42 & 4 & 6.41 \\
6 & -2451.01 & 5 & -2.08 \\
7 & -2453.09 & 6 & \\
\hline
\end{tabular}

\section{Are the Trajectories of Offending Among Matched Males Similar to Females?}

As with the trajectories derived from female offending, a five-group solution was chosen based on the log-likelihood values, low BIC value, and criteria for model solution (see Plan of Analyses; see Table 2). The six-group solution, which provided a marginally better fit, provided no trajectories that were unique in form or function, and one group was quite small. Figure 2 presents the five trajectories over time. The first group ( $7.9 \%$ of the sample) consisted of individuals who reported low levels of offending at every time point (low). The second group (33.9\%) showed moderate levels of offending, with gradual declines in offending in early adulthood (moderate).

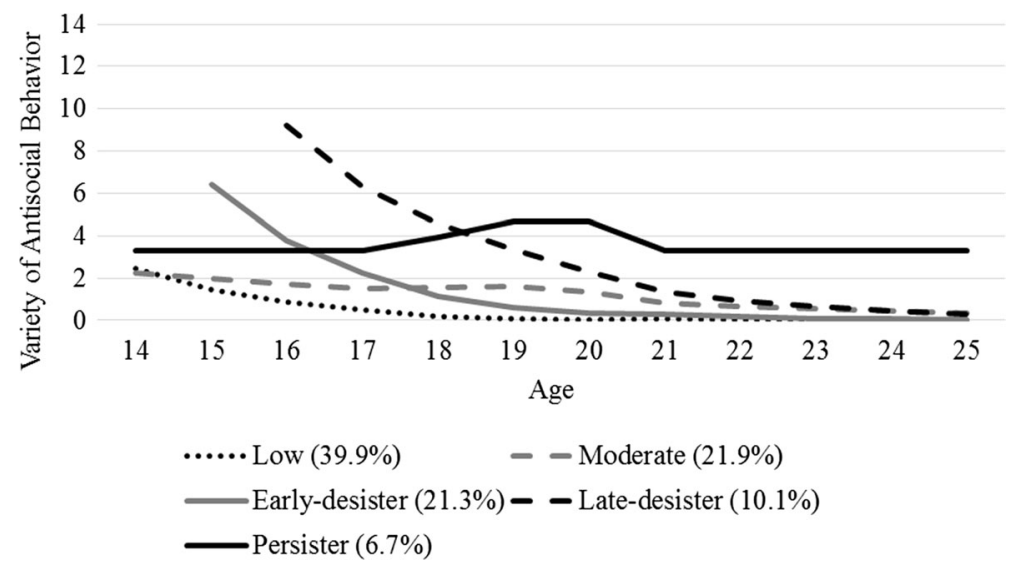

Fig. 1 Trajectories of offending among females only 


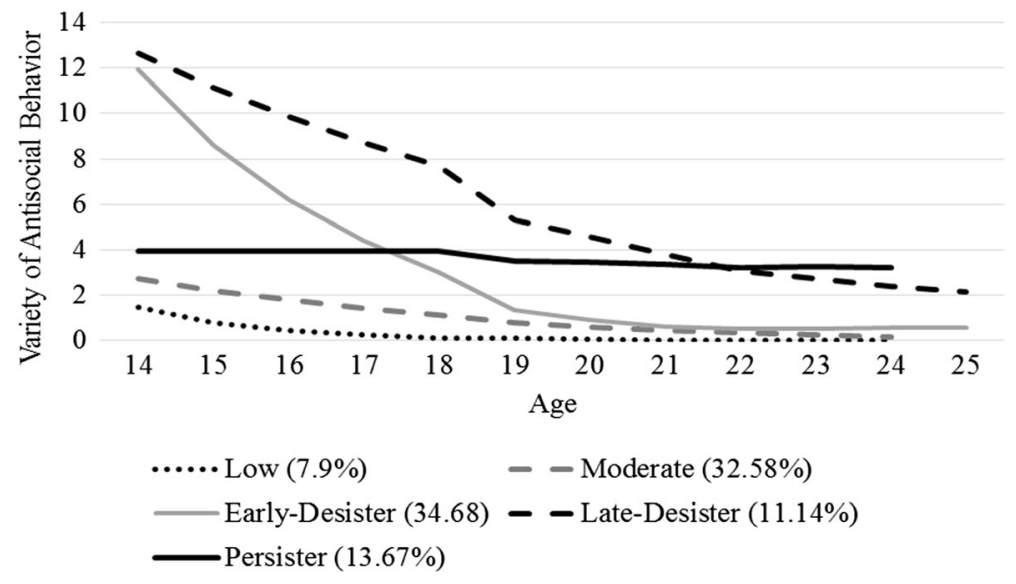

Fig. 2 Trajectories of offending among a matched sample of males only

The third group $(35.7 \%)$ engaged in high levels of antisocial behavior in early adolescence, but declined in antisocial behavior steadily and rapidly thereafter (earlydesister). The fourth group (10.5\%) engaged in high levels of antisocial behavior in mid-adolescence and then declined in antisocial behavior across the transition to adulthood (late-desister). Finally, the fifth group (12.9\%) reported relatively high levels of antisocial behavior consistently from ages 14 to 25 (Persisters). Posterior probabilities indicated that, on average, individuals were well matched to the groups to which they were assigned (average posterior probabilities were as follows: low $=.84$, moderate $=.44$, early-desister $=.88$, late-desister $=.96$, persister $=.91$ ).

In general, the overall pattern of findings between the matched male offending trajectories and the female offending trajectories is remarkably similar in the overall shape of antisocial behavior. The percentage of individuals identified in the samenamed trajectory group is fairly similar across the two sets of analyses except for the low-level group where there are more low-level female offenders $(40 \%)$ compared to low-level male offenders (roughly $8 \%$ ). The most obvious difference between the corresponding trajectories of males and females is in the level of offending. Specifically, the early- and late-desister male offending trajectories consist of individuals who engage in approximately 12-13 different types of offenses during early adolescence. In contrast, among the female offenders, the early- and late-desister trajectories consistently engage in just under 6-9 different types of offending during early adolescence.

\section{What are the Risk Factors for Persistent Female Offending?}

To examine if there were differences in the type of offenses committed by serious female offenders, Table 3 presents the mean proportion of aggressive (i.e., assault, fighting) and income offenses (i.e., theft, robbery) possible at each time point based on the 22 items from the self-report of offending measure. With few exceptions, the female persisting offenders report the greatest aggressive and income-related antisocial behavior at each time point. Table 4 presents the means and standard deviations of key risk factors by each offending trajectory group (low, moderate, early-desister, late-desister, and persister). 


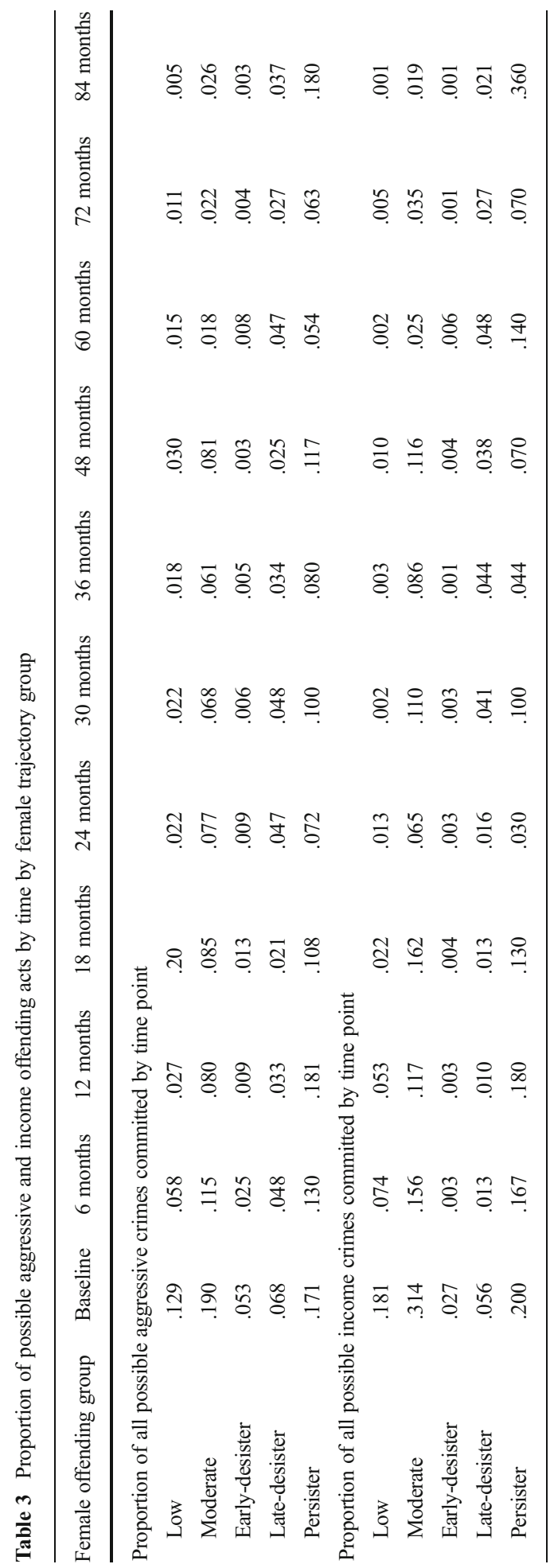


Table 4 Means of baseline covariates by trajectory group among females

\begin{tabular}{|c|c|c|c|c|c|}
\hline & \multicolumn{5}{|c|}{ Trajectory group membership } \\
\hline & $\begin{array}{l}\text { Low, } \\
n=71\end{array}$ & $\begin{array}{l}\text { Moderate, } \\
n=39\end{array}$ & $\begin{array}{l}\text { Early-desister, } \\
n=38\end{array}$ & $\begin{array}{l}\text { Late-desister, } \\
n=18\end{array}$ & $\begin{array}{l}\text { Persister, } \\
n=12\end{array}$ \\
\hline & $\mathrm{M}(\mathrm{SD})$ & $\mathrm{M}(\mathrm{SD})$ & $\mathrm{M}(\mathrm{SD})$ & $\mathrm{M}(\mathrm{SD})$ & $\mathrm{M}(\mathrm{SD})$ \\
\hline \multicolumn{6}{|l|}{ Demographic } \\
\hline Age & $15.73(1.03)$ & $15.69(1.08)$ & $16.53(.83)$ & $16.56(.62)$ & $15.92(1.24)$ \\
\hline Ethnicity white $\%$ & $25.4 \%$ & $33.3 \%$ & $23.7 \%$ & $27.8 \%$ & $33.3 \%$ \\
\hline Black $\%$ & $43.7 \%$ & $35.9 \%$ & $36.8 \%$ & $16.7 \%$ & $33.3 \%$ \\
\hline Hispanic\% $\%$ & $25.4 \%$ & $20.5 \%$ & $34.2 \%$ & $55.6 \%$ & $25.0 \%$ \\
\hline Parent deviance & $.33(.33)$ & $.53(.37)$ & $.40(.39)$ & $.36(.31)$ & $.52(.31)$ \\
\hline Prior criminal behavior & $7.89(.73)$ & $8.01(.91)$ & $8.28(.66)$ & $8.81(1.02)$ & $8.04(.69)$ \\
\hline \multicolumn{6}{|l|}{ Cognitive functioning } \\
\hline IQ & $84.15(13.97)$ & $84.38(13.07)$ & $84.11(16.54)$ & $90.22(13.20)$ & $83.50(15.82)$ \\
\hline Neurological functioning & $2.03(.94)$ & $2.05(1.12)$ & $1.97(1.08)$ & $1.72(1.13)$ & $1.83(1.03)$ \\
\hline \multicolumn{6}{|l|}{ Mental health } \\
\hline Mental health diagnosis & $.09(.28)$ & $.28(.46)$ & $.25(.44)$ & $.41(.51)$ & $.50(.52)$ \\
\hline Substance use diagnosis & $.13(.34)$ & $.28(.46)$ & $.38(.49)$ & $.24(.44)$ & $.08(.29)^{\mathrm{a}}$ \\
\hline \multicolumn{6}{|l|}{ Psychological } \\
\hline Psychopathy & $10.72(6.66)$ & $15.21(6.06)$ & $16.25(6.81)$ & $22.28(6.25)$ & $19.27(2.76)$ \\
\hline Legal cynicism & $1.68(.48)$ & $1.93(.66)$ & $1.82(.56)$ & $2.26(.51)$ & $2.05(.62)$ \\
\hline Legitimacy & $2.51(.58)$ & $2.49(.61)$ & $2.28(.59)$ & $2.21(.49)$ & $2.25(.80)$ \\
\hline Moral disengagement & $1.41(.27)$ & $1.58(.31)$ & $1.65(.38)$ & $1.76(.32)$ & $1.73(.59)$ \\
\hline Temperance & $.00(.87)$ & $.00(.86)$ & $.00(.94)$ & $.00(.91)$ & $.00(.88)$ \\
\hline Responsibility & $.00(.84)$ & $.00(.85)$ & $.00(.83)$ & $.00(.84)$ & $.00(.72)$ \\
\hline Perspective & $.00(.87)$ & $.00(.80)$ & $.00(.74)$ & $.00(.78)$ & $.00(.95)$ \\
\hline Exposure to violence & $3.04(2.37)$ & $4.23(2.55)$ & $4.87(2.76)$ & $7.00(2.33)$ & $6.83(2.69)$ \\
\hline \multicolumn{6}{|l|}{ Context and interpersonal relationships } \\
\hline Neighborhood disorder & $2.28(.84)$ & $2.39(.77)$ & $2.28(.85)$ & $2.59(.79)$ & $2.22(.89)$ \\
\hline Parental monitoring & $1.46(1.43)$ & $1.77(1.80)$ & $1.48(1.50)$ & $2.07(2.13)$ & $1.50(1.58)$ \\
\hline Parental hostility & $1.56(.46)$ & $1.70(.43)$ & $1.79(.55)$ & $2.00(.62)$ & $1.93(.64)$ \\
\hline Peer deviance & $1.68(.69)$ & $2.11(.72)$ & $2.36(.88)$ & $3.00(.59)$ & $2.77(.95)$ \\
\hline Romantic partner age difference & 2.35 (1.97) & $2.25(1.92)$ & $2.25(2.69)$ & $2.90(3.70)$ & $2.13(2.03)$ \\
\hline Romantic partner antisocial influence & $.02(.15)$ & $.23(.51)$ & $.41(.84)$ & $1.00(1.08)$ & $1.11(2.32)$ \\
\hline
\end{tabular}

${ }^{\text {a }}$ Only one persisting female met criteria for a diagnosis of substance use problem

Persisters Compared to Low, Moderate, Early-desister, and Late-desister Offending Groups Using multinomial logistic regression, we tested how demographic factors, cognitive functioning, mental health, psychological, and contextual factors were related to membership in each of the female trajectory groups (low, moderate, early-desister, and late-desister compared to being a persister). Table 5 presents the $\chi^{2}$ statistics and $p$ values for each variable. When a significant group difference was found (after an alpha correction), we conducted the planned contrasts test for the variable. These contrasts are presented in Table 6. 
Table 5 Multinomial logistic regression of female offending trajectory group membership

\begin{tabular}{|c|c|c|}
\hline Effect & $\chi^{2}$ & $p$ value \\
\hline \multicolumn{3}{|l|}{ Demographic } \\
\hline Age & 25.341 & $<.001$ \\
\hline Ethnicity & 12.856 & .380 \\
\hline Parent deviance & 9.602 & .048 \\
\hline Prior criminal behavior & 19.016 & .001 \\
\hline \multicolumn{3}{|l|}{ Cognitive functioning } \\
\hline IQ & 2.988 & .560 \\
\hline Neurological functioning & 1.804 & .772 \\
\hline \multicolumn{3}{|l|}{ Mental health } \\
\hline Mental health diagnosis & 17.330 & .002 \\
\hline Substance use diagnosis & 11.870 & .019 \\
\hline \multicolumn{3}{|l|}{ Psychological } \\
\hline Psychopathy & 52.175 & $<.001$ \\
\hline Legal cynicism & 17.700 & .001 \\
\hline Legitimacy & 7.410 & .116 \\
\hline Moral disengagement & 26.312 & $<.001$ \\
\hline Temperance & 25.498 & $<.001$ \\
\hline Responsibility & 4.793 & .309 \\
\hline Perspective & 22.871 & $<.001$ \\
\hline Exposure to violence & 45.153 & $<.001$ \\
\hline \multicolumn{3}{|l|}{ Context and interpersonal relationships } \\
\hline Neighborhood disorder & 2.691 & .611 \\
\hline Parental monitoring & 10.095 & .039 \\
\hline Maternal hostility & 14.834 & .005 \\
\hline Peer deviance & 64.996 & $<.001$ \\
\hline Romantic partner age difference ${ }^{a}$ & .679 & .954 \\
\hline Romantic partner antisocial influence ${ }^{a}$ & 24.315 & $<.001$ \\
\hline
\end{tabular}

The chi-square values are computed as -2 (LUR-LR) $\sim \chi^{2}$, where LUR and LR are the maximized loglikelihoods of the full and restricted models, respectively. All tests have four degrees of freedom. The reference group is female persisters. All differences remained significant after using the Benjamini-Hochberg correction for multiple tests. All models were conducted separately

${ }^{a}$ A smaller sample size was used for this analysis because not all females reported a romantic relationship at the baseline interview. Low group: $N=42$; moderate group: $N=27$; early-desister: $N=26$; late-desister: $N=13$; persister: $N=9$

Among demographic factors, age, parent deviance, and prior criminal behavior differed between female offending trajectory groups. Youths whose parents engaged in criminal behavior were somewhat more likely to be in the persister trajectory compared to the low group trajectory (trend level, $p<.071$ ). In addition, older youth were more likely to belong to the early-desister and late-desister (trend level, $p<.070$ ) trajectory compared to the persisting trajectory. Prior criminal behavior also distinguished the late-desister trajectory from the persister trajectory: younger ages of 
criminal behavior onset were associated with membership in the persister offending trajectory compared to the late-desister offending trajectory. Ethnicity was not associated with differential membership in trajectory groups.

Cognitive functioning (IQ and neurological functioning) did not differ among low, moderate, early-desister, late-desister, and persisting female offenders.

Having a history of mental health diagnosis was associated with membership in the persister offending trajectory compared to the low-desister trajectory. There were no other significant group differences.

With respect to psychological factors, legitimacy and responsibility did not differ between the trajectory groups. In contrast, psychopathy, legal cynicism, moral disengagement, temperance, perspective, and exposure to violence distinguished among the female offending trajectories. Psychopathy, legal cynicism, moral disengagement, and temperance were only different between the low-desister group and the persister group; lower levels of psychopathy, legal cynicism, moral disengagement, victimization, and temperance were associated with being members of the low-desister group compared to the persister group. In other words, the more psychopathic, cynical of the law, morally disengaged, victimized, and intemperate a female appeared to be, the more likely she was to be classified as a persister. It is important to note that greater lifetime exposure to violence and less perspective (i.e., the inability to think long term) was associated with being a member of the persister group compared to the low, moderate, and earlydesister offending trajectories.

With regard to contextual factors and interpersonal relationships, parental monitoring, maternal hostility, peer delinquent behavior, and romantic partner antisocial influence were all associated with differences in female offending trajectories. Greater parental monitoring was associated with lower probability of membership in the earlydesister group compared to the persister group. Higher maternal hostility was associated with membership in the low desister group compared to the persister group. Females who associated with delinquent peers were more likely to report membership in the persister trajectory group compared to the low, moderate, or early-desister trajectory groups. Dating a romantic partner who exerted high levels of antisocial influence was associated with membership in the persister offending trajectory compared to the low or moderate desister trajectory group. Neighborhood disorder and age difference between the participant and her romantic partner were unrelated to offending trajectory group.

\section{Are the Risk Factors for Persistent Offending Among Females Similar to Matched Males?}

Table 7 presents the means and standard deviations of key variables by each offending trajectory group (low, moderate, early-desister, late-desister, and persister). No males in the moderate group reported romantic partners who had antisocial influence. As such, our test of the romantic partner antisocial influence variable is limited to the low, early-desister, and late-desister groups compared to the persisters.

Persisters Compared to Low, Moderate, Early-Desister, and Late-Desister Offending Groups In our sample of males matched to delinquent females, we used multinomial logistic regression to compare each trajectory group to persisting males. 
Table 6 Planned contrasts of low, moderate, early-desister, and late-desister compared to persister of femaleonly trajectories

\begin{tabular}{|c|c|c|c|c|}
\hline Low vs. persister & $B$ & Wald & $\operatorname{Exp}(\beta)$ & $p$ value \\
\hline Age & -.182 & .338 & .833 & .561 \\
\hline Parent deviance & -1.547 & 3.255 & .213 & .071 \\
\hline Prior criminal behavior & -.310 & .515 & .734 & .473 \\
\hline Substance use diagnosis & .535 & .234 & 1.707 & .628 \\
\hline Mental health diagnosis & -2.351 & 10.718 & .095 & .001 \\
\hline Psychopathy & -.212 & 14.144 & .809 & $<.001$ \\
\hline Legal cynicism & -1.204 & 4.668 & .300 & .031 \\
\hline Moral disengagement & -2.980 & 10.709 & .051 & .001 \\
\hline Temperance & .905 & 5.552 & 2.471 & .018 \\
\hline Perspective & 1.602 & 16.285 & 4.961 & $<.001$ \\
\hline Exposure to violence & -.575 & 17.702 & .563 & $<.001$ \\
\hline Parental monitoring & -.384 & .641 & .681 & .424 \\
\hline Maternal hostility & -1.490 & 6.507 & .225 & .011 \\
\hline Peer deviance & -4.926 & 31.460 & .007 & $<.001$ \\
\hline Romantic partner antisocial influence & -2.832 & 7.421 & .059 & .006 \\
\hline \multicolumn{5}{|l|}{ Moderate vs. persister } \\
\hline Age & -.221 & .447 & .802 & .504 \\
\hline Parent deviance & .063 & .005 & 1.065 & .942 \\
\hline Prior criminal behavior & -.054 & .014 & .947 & .940 \\
\hline Substance use diagnosis & 1.705 & 2.409 & 5.500 & .121 \\
\hline Mental health diagnosis & -.934 & 1.898 & .393 & .168 \\
\hline Psychopathy & -.100 & 3.227 & .905 & .072 \\
\hline Legal cynicism & -.367 & .412 & .693 & .521 \\
\hline Moral disengagement & -1.096 & 1.514 & .334 & .219 \\
\hline Temperance & -.056 & .019 & .956 & .889 \\
\hline Perspective & 1.017 & 6.666 & 2.765 & .010 \\
\hline Exposure to violence & -.378 & 7.747 & .685 & .005 \\
\hline Parental monitoring & -.532 & 1.131 & .588 & .287 \\
\hline Maternal hostility & -.743 & 1.644 & .476 & .200 \\
\hline Peer deviance & -2.600 & 10.570 & .074 & .001 \\
\hline Romantic partner antisocial influence & -.909 & 4.175 & .403 & .041 \\
\hline \multicolumn{5}{|l|}{ Early-desister vs. persister } \\
\hline Age & .696 & 3.903 & 2.006 & .048 \\
\hline Parent deviance & -.898 & 1.003 & .407 & .317 \\
\hline Prior criminal behavior & .386 & .762 & 1.471 & .383 \\
\hline Substance use diagnosis & 1.918 & 3.028 & 6.810 & .082 \\
\hline Mental health diagnosis & -1.099 & 2.507 & .333 & .113 \\
\hline Psychopathy & -.075 & 1.818 & .928 & .178 \\
\hline Legal cynicism & -.725 & 1.555 & .484 & .212 \\
\hline Moral disengagement & -.563 & .422 & .570 & .516 \\
\hline Temperance & .324 & .663 & 1.382 & .415 \\
\hline
\end{tabular}


Table 6 (continued)

\begin{tabular}{|c|c|c|c|c|}
\hline Low vs. persister & $B$ & Wald & $\operatorname{Exp}(\beta)$ & $p$ value \\
\hline Perspective & .884 & 5.180 & 2.421 & .023 \\
\hline Exposure to violence & -.286 & 4.572 & .752 & .032 \\
\hline Parental monitoring & -1.030 & 4.235 & .357 & .040 \\
\hline Parental hostility & -.404 & .524 & .667 & .469 \\
\hline Peer deviance & -2.032 & 7.014 & .131 & .008 \\
\hline Romantic partner antisocial influence & -.517 & 2.250 & .596 & .134 \\
\hline \multicolumn{5}{|l|}{ Late-desister vs. persister } \\
\hline Age & .735 & 3.276 & 2.086 & .070 \\
\hline Parent deviance & -1.243 & 1.417 & .288 & .234 \\
\hline Prior criminal behavior & .967 & 4.152 & 2.631 & .042 \\
\hline Substance use diagnosis & 1.219 & 1.048 & 3.385 & .306 \\
\hline Mental health diagnosis & -.357 & .221 & .700 & .638 \\
\hline Psychopathy & .078 & 1.538 & 1.081 & .215 \\
\hline Legal cynicism & .598 & .868 & 1.818 & .352 \\
\hline Moral disengagement & .231 & .061 & 1.260 & .805 \\
\hline Temperance & -.324 & .498 & .723 & .480 \\
\hline Perspective & .655 & 2.336 & 1.926 & .126 \\
\hline Exposure to violence & .027 & .032 & 1.027 & .858 \\
\hline Parental monitoring & -1.065 & 3.639 & .345 & .056 \\
\hline Maternal hostility & .175 & .087 & 1.192 & .768 \\
\hline Peer deviance & -.369 & .247 & .692 & .619 \\
\hline Romantic partner antisocial influence & -.043 & .025 & .958 & .873 \\
\hline
\end{tabular}

Reference group is female persisters. All models were conducted separately

Table 8 presents the overall tests of each variable of interest while Table 9 presents the planned contrasts for those tests where there was a significant omnibus chi-square between the groups. Planned contrasts compared the low, moderate, early-desister, and late-desister groups to the persister group.

Demographic factors distinguished between the groups. Specifically, age, parent deviance, and prior criminal behavior differed between male trajectory groups. Low offenders were younger than persisters, but there were no other significant differences in age. Low offenders also reported lower parental deviance compared to persister males, but there were no differences between persisting males and moderate, early-, and late-desisters in parental deviance. Compared to persisters, low offenders had fewer criminal priors, while the latedesisters had more criminal priors. There were no differences by race or ethnicity across the five trajectory groups.

Cognitive functioning as assessed by IQ did not differ between groups. However, there were differences based on neurological functioning. Males in the low group exhibited higher levels of neurological functioning compared to persisters.

With respect to mental health, substance use diagnosis differentiated the groups while history of mental health diagnosis did not. No significant differences emerged in our planned 
Table 7 Means of baseline covariates by trajectory group among males

\begin{tabular}{|c|c|c|c|c|c|}
\hline & \multicolumn{5}{|c|}{ Trajectory group membership } \\
\hline & $\begin{array}{l}\text { Low, } \\
n=12\end{array}$ & $\begin{array}{l}\text { Moderate, } \\
n=58\end{array}$ & $\begin{array}{l}\text { Early-desister, } \\
n=61\end{array}$ & $\begin{array}{l}\text { Late-desister, } \\
n=18\end{array}$ & $\begin{array}{l}\text { Persister, } \\
n=22\end{array}$ \\
\hline & $\mathrm{M}(\mathrm{SD})$ & $\mathrm{M}(\mathrm{SD})$ & $\mathrm{M}(\mathrm{SD})$ & $\mathrm{M}(\mathrm{SD})$ & $\mathrm{M}(\mathrm{SD})$ \\
\hline \multicolumn{6}{|l|}{ Demographic } \\
\hline Age & $15.33(.99)$ & $15.71(.96)$ & $16.20(1.01)$ & $16.22(.94)$ & $16.05(1.00)$ \\
\hline Ethnicity white\% & $25 \%$ & $20.7 \%$ & $25 \%$ & $27.8 \%$ & $40.9 \%$ \\
\hline Black & $50 \%$ & $46.6 \%$ & $50 \%$ & $22.2 \%$ & $27.3 \%$ \\
\hline Hispanic & $16.7 \%$ & $27.6 \%$ & $16.7 \%$ & $38.9 \%$ & $31.8 \%$ \\
\hline Parent deviance & $.17(.16)$ & $.27(.29)$ & $.39(.37)$ & $.52(.43)$ & $.41(.35)$ \\
\hline Prior criminal behavior & $7.63(.43)$ & $7.95(.85)$ & $8.61(1.13)$ & $9.25(1.36)$ & $8.27(.92)$ \\
\hline \multicolumn{6}{|l|}{ Cognitive functioning } \\
\hline IQ & $81.50(10.21)$ & $84.66(12.10)$ & $88.33(13.03)$ & $87.06(13.25)$ & $87.23(15.78)$ \\
\hline Neurological functioning & $3.00(.85)$ & $2.02(.86)$ & $2.10(.95)$ & $2.24(.97)$ & $2.18(1.05)$ \\
\hline \multicolumn{6}{|l|}{ Mental health } \\
\hline Mental health diagnosis & $.08(.29)$ & $.10(.31)$ & $.23(.42)$ & $.17(.38)$ & $.05(.22)$ \\
\hline Substance use diagnosis & $.08(.29)$ & $.20(.40)$ & $.42(.50)$ & $.39(.50)$ & $.38(.50)$ \\
\hline \multicolumn{6}{|l|}{ Psychological } \\
\hline Psychopathy & $8.08(4.12)$ & $12.71(7.99)$ & $18.55(5.67)$ & $22.72(5.80)$ & $16.50(6.49)$ \\
\hline Legal cynicism & $1.82(.66)$ & $1.86(.44)$ & $2.25(.65)$ & $2.28(.64)$ & $2.18(.59)$ \\
\hline Legitimacy & $2.54(.55)$ & $2.27(.46)$ & $2.14(.44)$ & $2.08(.59)$ & $2.34(.48)$ \\
\hline Moral disengagement & $1.50(.16)$ & $1.54(.31)$ & $1.68(.28)$ & $1.93(.47)$ & $1.75(.40)$ \\
\hline Temperance & $1.15(.86)$ & $.23(.83)$ & $-.22(.68)$ & $-.85(.69)$ & $.08(.66)$ \\
\hline Responsibility & $.09(.89)$ & $.08(.85)$ & $-.01(.75)$ & $-.38(.80)$ & $.10(.74)$ \\
\hline Perspective & $.57(.69)$ & $.15(.78)$ & $-.05(.77)$ & $-.83(.80)$ & $.10(.78)$ \\
\hline Exposure to violence & $2.58(1.73)$ & $4.57(2.77)$ & $6.44(2.56)$ & $8.33(1.57)$ & $5.14(2.85)$ \\
\hline \multicolumn{6}{|l|}{ Context and interpersonal relationships } \\
\hline Neighborhood disorder & $2.06(.59)$ & $2.11(.77)$ & $2.44(.75)$ & $2.95(.73)$ & $2.36(.58)$ \\
\hline Parental monitoring & $1.50(1.58)$ & $1.64(1.59)$ & $1.87(1.89)$ & $2.90(2.47)$ & $1.33(1.29)$ \\
\hline Maternal hostility & $1.29(.26)$ & $1.45(.37)$ & $1.66(.46)$ & $1.73(.44)$ & $1.68(.41)$ \\
\hline Peer deviance & $1.00(.28)$ & $1.18(.51)$ & $1.51(.48)$ & $1.95(.60)$ & $1.35(.49)$ \\
\hline Romantic partner age difference & $-.20(.84)$ & $.29(1.73)$ & $-.23(1.52)$ & $.89(1.97)$ & $.57(3.46)$ \\
\hline Romantic partner antisocial influence & $.20(.45)$ & $.00(.00)^{\mathrm{a}}$ & $.24(.71)$ & $.82(1.25)$ & $.20(.42)$ \\
\hline
\end{tabular}

${ }^{a}$ No males in the moderate group reported romantic partners who had antisocial influence

contrasts of persisters compared to each of the other groups, suggesting the difference lies in comparisons not of central interest here.

Except for responsibility, all of the psychological variables were found to differ between the trajectory groups: psychopathy, legal cynicism, legitimacy, moral disengagement, temperance, perspective, and exposure to violence. Psychopathy was significantly lower in the low group compared to the persisters. No other significant 
Table 8 Multinomial logistic regression of male offending trajectory group membership

\begin{tabular}{|c|c|c|}
\hline Effect & $\chi^{2}$ & $p$ value \\
\hline \multicolumn{3}{|l|}{ Demographic } \\
\hline Age & 13.268 & .010 \\
\hline Ethnicity & 12.086 & .439 \\
\hline Parent deviance & 12.857 & .012 \\
\hline Prior criminal behavior & 32.075 & $<.001$ \\
\hline \multicolumn{3}{|l|}{ Cognitive functioning } \\
\hline IQ & 4.311 & .366 \\
\hline Neurological functioning & 11.142 & .025 \\
\hline \multicolumn{3}{|l|}{ Mental health } \\
\hline Substance use diagnosis & 11.333 & .023 \\
\hline Mental health diagnosis & 6.636 & .156 \\
\hline \multicolumn{3}{|l|}{ Psychological } \\
\hline Psychopathy & 52.619 & $<.001$ \\
\hline Legal cynicism & 18.399 & .001 \\
\hline Legitimacy & 10.411 & .034 \\
\hline Moral disengagement & 22.036 & $<.001$ \\
\hline Temperance & 55.057 & $<.001$ \\
\hline Responsibility & 5.312 & .257 \\
\hline Perspective & 27.755 & .001 \\
\hline Exposure to violence & 49.532 & $<.001$ \\
\hline \multicolumn{3}{|l|}{ Context and interpersonal relationships } \\
\hline Neighborhood disorder & 20.742 & $<.001$ \\
\hline Parental monitoring & 15.174 & .004 \\
\hline Maternal hostility & 18.962 & .001 \\
\hline Peer deviance & 40.003 & $<.001$ \\
\hline Romantic partner age difference $^{\mathrm{a}}$ & 3.457 & .484 \\
\hline Romantic partner antisocial influence ${ }^{a}$ & 17.080 & .002 \\
\hline
\end{tabular}

The chi-square values are computed as -2 (LUR-LR) $\sim \chi^{2}$, where LUR and LR are the maximized loglikelihoods of the full and restricted models, respectively. All tests have four degrees of freedom. The reference group is male persisters. All differences remained significant after using the Benjamini-Hochberg correction for multiple tests. All models were conducted separately

${ }^{\text {a }}$ A smaller sample size was used for this analysis because not all males reported a romantic relationship at the baseline interview: low group: $N=5$; moderate group: $N=24$; early-desister: $N=31$; late-desister: $N=9$; persister: $N=7$

differences were observed. Males in the moderate offending group reported significantly lower legal cynicism compared to persisters, but no other contrasts were significant. Although there was a difference between perceptions of police legitimacy between our groups, none of the contrasts were significant, indicating that the difference was driven by a contrast not of central interest to the present paper. Moral disengagement was significantly lower in the low and moderate groups compared to the persisters. Similarly, the low group reported significantly higher levels of 
Table 9 Planned contrasts of low, moderate, early-desister, and late-desister compared to persister male offending trajectories

\begin{tabular}{|c|c|c|c|c|}
\hline Low vs. persister & $B$ & Wald & $\operatorname{Exp}(\beta)$ & $p$ value \\
\hline Age & -.709 & 3.721 & .492 & .054 \\
\hline Parent deviance & -2.731 & 3.909 & .065 & .048 \\
\hline Prior criminal behavior & -.921 & 4.205 & .398 & .040 \\
\hline Neurological functioning & .965 & 5.335 & 2.624 & .021 \\
\hline Substance use diagnosis & -1.912 & 2.829 & .148 & .093 \\
\hline Psychopathy & -.235 & 10.962 & .914 & .023 \\
\hline Legal cynicism & -1.171 & 3.057 & .310 & .080 \\
\hline Legitimacy & .969 & 1.483 & 2.636 & .223 \\
\hline Moral disengagement & -2.557 & 4.128 & .078 & .042 \\
\hline Temperance & 1.734 & 10.820 & 5.665 & .010 \\
\hline Perspective & .812 & 2.852 & 2.252 & .091 \\
\hline Exposure to violence & -.390 & 6.283 & .677 & .012 \\
\hline Neighborhood disorder & -.588 & 1.340 & .556 & .247 \\
\hline Parental monitoring & 1.430 & 5.918 & 4.179 & .015 \\
\hline Maternal hostility & -3.472 & 6.473 & .031 & .011 \\
\hline Peer deviance & -2.553 & 5.428 & .078 & .020 \\
\hline Romantic partner antisocial influence & .001 & .001 & 1.00 & 1.00 \\
\hline \multicolumn{5}{|l|}{ Moderate vs. persister } \\
\hline Age & -.345 & 1.784 & .708 & .182 \\
\hline Parent deviance & -1.249 & 2.796 & .287 & .094 \\
\hline Prior criminal behavior & -.426 & 2.239 & .653 & .135 \\
\hline Neurological functioning & -.192 & .500 & .825 & .479 \\
\hline Substance use diagnosis & -.901 & 2.571 & .406 & .109 \\
\hline Psychopathy & -.090 & 5.158 & .914 & .914 \\
\hline Legal cynicism & -1.009 & 5.012 & .364 & .025 \\
\hline Legitimacy & -.322 & .365 & .725 & .546 \\
\hline Moral disengagement & -2.046 & 6.610 & .129 & .010 \\
\hline Temperance & .239 & .529 & 1.270 & .467 \\
\hline Perspective & .091 & .075 & 1.095 & .784 \\
\hline Exposure to violence & -.078 & .699 & .925 & .403 \\
\hline Neighborhood disorder & -.476 & 1.880 & .621 & .170 \\
\hline Parental monitoring & .133 & .169 & 1.142 & .681 \\
\hline Maternal hostility & -1.481 & 5.198 & .227 & .023 \\
\hline Peer deviance & -.983 & 2.704 & .374 & .100 \\
\hline Romantic partner antisocial influence & $-^{\mathrm{a}}$ & & & \\
\hline \multicolumn{5}{|l|}{ Early-desister vs. persister } \\
\hline Age & .168 & .415 & 1.183 & .520 \\
\hline Parent deviance & -.135 & 2.796 & .874 & .847 \\
\hline Prior criminal behavior & .343 & 1.706 & 1.409 & .192 \\
\hline Neurological functioning & -.095 & .125 & .901 & .724 \\
\hline Substance use diagnosis & -.178 & .117 & .733 & 1.195 \\
\hline
\end{tabular}


Table 9 (continued)

\begin{tabular}{|c|c|c|c|c|}
\hline Low vs. persister & $B$ & Wald & $\operatorname{Exp}(\beta)$ & $p$ value \\
\hline Psychopathy & .045 & 1.450 & 1.046 & .228 \\
\hline Legal cynicism & .187 & .193 & 1.206 & .660 \\
\hline Legitimacy & -.871 & 2.647 & .419 & .104 \\
\hline Moral disengagement & -.603 & .687 & .547 & .407 \\
\hline Temperance & -.565 & 2.772 & .568 & .096 \\
\hline Perspective & -.269 & .665 & .764 & .415 \\
\hline Exposure to violence & .192 & 3.997 & 1.212 & .046 \\
\hline Neighborhood disorder & .140 & .170 & 1.150 & .680 \\
\hline Parental monitoring & -.129 & .160 & .879 & .689 \\
\hline Maternal hostility & -.080 & .020 & .923 & .886 \\
\hline Peer deviance & .667 & 1.526 & 1.949 & .217 \\
\hline Romantic partner antisocial influence & .118 & .032 & 1.126 & .858 \\
\hline \multicolumn{5}{|l|}{ Late-desister vs. persister } \\
\hline Age & .197 & .342 & 1.218 & .559 \\
\hline Parent deviance & -1.058 & 1.235 & .347 & .266 \\
\hline Prior criminal behavior & .784 & 6.441 & 2.190 & .011 \\
\hline Neurological functioning & .061 & .031 & 1.063 & .860 \\
\hline Substance use diagnosis & -.034 & .003 & 1.034 & .959 \\
\hline Psychopathy & -.060 & 1.114 & .942 & .291 \\
\hline Legal cynicism & .280 & .265 & 1.206 & .607 \\
\hline Legitimacy & -1.150 & 2.818 & .317 & .093 \\
\hline Moral disengagement & 1.282 & 2.157 & 3.603 & .142 \\
\hline Temperance & -2.030 & 13.955 & .131 & $<.001$ \\
\hline Perspective & -1.521 & 11.668 & .219 & .001 \\
\hline Exposure to violence & .607 & 13.147 & 1.835 & $<.001$ \\
\hline Neighborhood disorder & 1.177 & 6.128 & 3.246 & .013 \\
\hline Parental monitoring & -.592 & 1.946 & .553 & .163 \\
\hline Maternal hostility & .258 & .137 & 1.294 & .711 \\
\hline Peer deviance & 1.802 & 8.160 & 6.064 & .004 \\
\hline Romantic partner antisocial influence & .781 & 1.356 & 2.18 & .244 \\
\hline
\end{tabular}

Reference group is male persisters. All models were conducted separately

${ }^{\text {a }}$ No moderate offenders reported romantic partners with antisocial influence. As such, this parameter could not be estimated

temperance, while the late-desisters reported significantly lower temperance and lower perspective, when compared to persisters. No other comparisons were significant for temperance and perspective. While exposure to violence was significantly lower among low offenders compared to persisters, the early- and late-desisters reported higher levels of exposure to violence than persisters at the baseline interview.

Finally, we tested differences in contextual and interpersonal factors between groups. Parental monitoring was greater among low offenders than persisters, but no other contrasts reached statistical significance. Males in the low and moderate groups 
reported lower levels of maternal hostility than males in the persister category. There were no differences between early-desisters, late-desisters, and persisters in maternal hostility. Affiliation with deviant peers was significantly lower in the low and moderate offending groups compared to persisters, but significantly higher in the late-desisters compared to persisters.

In general, across a wide variety of factors, evidence suggests that among males, those in the low and moderate offending trajectories are less likely to report risk, whereas late-desisters report higher levels of risk compared to persisters.

\section{Discussion}

Given the increased proportion of girls entering the juvenile justice system, understanding the developmental trajectories of female offenders has been essential. The results of the present study indicate quite clearly that, similar to male offenders [44-46], there is great heterogeneity in criminal behavior among serious female offenders. Most importantly, we find that even among a sample of serious female offenders, the majority of these young women desist in their criminal behavior over time. However, as with males, a very small proportion (roughly $7 \%$ ) of females' criminal careers persists into their mid-twenties. While trying to predict who will desist and who will persist has been a difficult task for both researchers and practitioners, three themes emerge from our study. Specifically, we find that females who persist in their criminal careers tend to be exposed to more violence in their lives, have more mental health problems, and experience more adversarial interpersonal relationships compared to those who desist.

Despite the evidence that female criminal careers follow the same overall patterns of criminal behavior as males, we find that the level of female offending does not rise to the same level as male offending. Specifically, as seen in previous research, the males in our sample offend at higher rates than the females $[7,16]$. This sex difference in level of offending, however, is not as pronounced as in other research. We attribute this convergence in offending behavior on our ability to match our female offenders with our male offenders. As seen in the approach used by Giordano [19], using similarly situated males and females provides a more appropriate comparison between the two sexes and allows for a more clear interpretation of the findings when differences are observed. Also, as noted by Laub and Sampson [35], in order to truly understand the desistance process, samples need to include those who reach a certain threshold of serious and frequent criminal offending. As such, our inclusion of only felony level or serious female offenders provides a clearer picture of the desistance, as well as persistence, pathway.

To illustrate this point, in an analysis of all the males in the Pathways sample $(N=$ 1170), a five-trajectory solution was also derived and is remarkably similar in overall pattern as was observed with the smaller sample of males as well as female-only derived trajectories (Fig. 2; see [45]). In the current analyses, using the sample of males matched on committing offense, race, and age, the percentage of males identified in the same-named trajectory group is generally similar to females, although females were more likely than males to be in the low group (40 vs. $8 \%$, respectively). Specifically, the male early- and late-desister trajectories consist of individuals who 
engage in approximately 12 different types of offenses whereas the highest level of offending ever observed among females does not reach beyond nine different types of offenses. Also, the late-desister group of female offenders eventually tapers off in their criminal behavior whereas the late-desister male offender group never completely desists from crime. In the present study, when we derive trajectories of antisocial behavior of males from the Pathways sample who are similar to the serious offending females, these differences in level are substantially diminished. Thus, studies that document widespread gender differences in the prevalence of male and female offending may do so because at the population level, males appear to offending more. When males and females are drawn from similar backgrounds, this sex difference in patterns of criminal offending is reduced.

While it is notable that the developmental patterning of antisocial behavior is comparable between males and females, particularly within our matched-sample analyses, it is important to point out that the correlates of these offending trajectories remain quite different between the sexes. Although traditional approaches to understanding criminal heterogeneity suggest that persistence is due to neurological and cognitive risk and adolescent-limited offending is a more normative developmental phenomenon born out of a desire to feel more adult-like [39], the findings of this study draw into question the "normative nature" of serious adolescent offending, even among those who desist. Indeed, taken cumulatively across analyses, we find many circumstances where persisters and desisters are comparable in the level of environmental risk. The most notable differences occur between the lowest offending groups and the persisters (for both males and females), but the number of differences between male and female desisters and persisters is modest. This is important for two reasons. First, it suggests that it is very difficult to distinguish between persisters and desisters during adolescence. Second, it highlights that serious offending, and offending more generally, during the teen years is not simply developmental normative [58] but is the product of exposure to some environmental risk in childhood or adolescence. As such, what is important in the present study is to highlight the specific environmental factors that may contribute to one pathway that turns out developmentally appropriate (i.e., those that offend at high rates during the teen years but then cease offending as adults) and another pathway that continues to be concerning well into adulthood (i.e., those who offend at high rates during adolescence and persist on this pathway). We briefly highlight these similarities and differences across trajectory groups with the hope of identifying specific mechanisms that may explain heterogeneity in these patterns of crime, with the important caveat that all of the moderate, early-desisters, late-desisters, and persisters appear to exhibit some level of risk in their lives.

We do not find evidence that neurological or cognitive factors differ between the trajectories of female offenders. However, for males, the persistent male offenders are more likely to have neurological deficits than the low offending males. While not assessed during early childhood, it is important to note that environmental factors assessed during adolescence are important for determining female offending trajectories. Specifically, persistent female offenders tend to engage with deviant peers, experience more antisocial influence from romantic partners, and have higher rates of exposure to violence compared to girls from other trajectory groups. In addition, we find that persistent female offenders are also more likely to suffer from a mental health problem, exhibit psychopathic characteristics and lack the ability to think long term. 
Our findings are consistent with risk factors for offending more generally that have been suggested in prior literature. For example, decades of research have documented the relation between delinquency and ones' association with deviant peers [14, 72]. As was found in the present study, in addition to the influence of ones' peers, deviant romantic partners also serve as a unique source of antisocial influence associated with youths' engagement in delinquency [23]. Of relevance to the sex comparisons of the present study, past research suggests female adolescents may be more vulnerable to the influence of a romantic partner than male adolescents, at least for minor acts of deviance $[23,43]$. Also consistent with our findings is research that finds youth who are exposed to violence, specifically domestic violence, are more likely to be referred to the juvenile court than non-exposed youth [25]. These findings are also in line with prior work demonstrating the association between mental health disorders and delinquency, as a recent review finds as many as $33-80 \%$ of incarcerated youthful offenders have a mental health disorder [37]. Finally, the present results are consistent with the well-established finding in criminological research that delinquents tend to focus on the more immediate future at the expense of more long-term thinking and planning [8].

Using identical predictors of trajectory group membership for males, we are able to observe some similarities between our matched sample of males and females in trajectory membership with regard to environmental risk. For example, similar to the females, the males in the persister group have experienced greater rates of victimization compared to males in the low group. Prior research suggests that although victimization is a risk factor for both male and female offending, the reaction to these stressors may not be ([4]; Krustchnitt, 2013). However, for the males only, an opposite pattern in exposure to violence is observed between the persister group and the early- vs. latedesister group. Specifically, males in the early- and late-desister group are more likely to have been exposed to violence than the persister group. This higher rate of victimization may explain why the males in these two groups (the early- and late-desister group) exhibit such high rates of offending (12 different types of offending behavior) early in their adolescent years compared to the persister group (4 types of offending). Research indicates that it is the rate of victimization, rather than simply being victimized or not, that more accurately explains delinquency risk such that the greater the exposure to violence, the greater the risk of offending [50].

Interpersonal relationships, particularly with peers, are also an environmental force that influences both male and female offending in similar ways. Specifically, peer deviance discriminates among trajectory groups, with more delinquent peer associations predicting membership in the male and female persister group compared to other trajectory groups. An exception to this rule, however, exists - again - for males with the late-desister group exhibiting higher rates of deviancy among their peers than the persistent group. Again, this may help explain the level of offending we observe among these high level offending males during the early adolescent years. It is important to note that romantic relationships are more predictive of female persistent offending and are unrelated to persistent male offending. In fact, males did not report any antisocial influence from their girlfriends at all. Thus, persistent female offenders are more sensitive to all their peer interpersonal relationships (friend and romantic) while male offenders are more likely to be influenced by the negative influences of only their friends.

Despite these similarities, there are also interesting differences between the predictors of female and male persistence. For example, among female offenders, diagnosis of a mental 
health disorder is linked with persistent offending compared to those who desist early. In contrast, as observed among serious male offenders, it is substance use disorder, not a mental health disorder, that predicts membership in the persisting offending trajectory. Only 1 female had a substance use disorder, suggesting that mental health disorders may be more salient for persistent female offending than substance use disorders.

While comparisons between male and female patterns of crime are important, it is also important to distinguish among female offenders themselves. Most notably, the best way to differentiate between females who persist and those who desist is based on their exposure to violence, their ability to think about the future, and their deviant peer relationships. Specifically, persistent female offenders have extensive histories as being either a victim or witness of a violent act compared to females who were either low-level offenders, moderate-level offenders, or early-desisters. Exposure to uncontrollable stressors and abuse are undeniably common precursors to conduct problems in female offenders (Tolin and Foa, 2006). In addition, dysfunction in girls' stress-coping mechanisms may further exacerbate the negative effects of childhood trauma and victimization (Susman and Pajer, 2004). In other words, female offenders have not only experienced higher rates of victimization but they also tend to have more limited abilities to cope with such stressors, thereby magnifying their effect (Dornfeld and Kruttschnitt, 1992). The high rate of victimization among the persistent female offenders suggests that treatment should be targeted toward addressing experiences of victimization.

The most surprising finding between the different female offending trajectory groups was between the late-desister females and persistent females. Specifically, the only significant difference between these two trajectory groups was in their prior criminal behavior, with persistent female offenders exhibiting lower rates of prior criminal behavior than the late-desisters. There is also a slight age difference between these two groups, with the persistent female offenders being about a half a year younger than the late-desister group. As prior research has shown, one of the best predictors of future delinquency is a history of antisocial behavior in childhood [5]. Here, the late-desister group has a more varied criminal past, but they started their criminal career later and are less likely to persist, despite their wider repertoire of past offenses. Indeed, the lack of differences noted between these groups suggests that any evidence of high levels of offending during the teen years is not developmentally normative, as similar levels of environmental risk are reported between these two groups at the baseline assessment. Whether persisters experience earlier or more cumulative levels of risk across time is an interesting and important theoretical question.

While the present study is strengthened by its focus on female offenders, longitudinal assessment, and advanced analytic technique, there are limitations that should also be considered. First, the measures are predominantly self-report, including our primary outcome variable of self-reported offending. While official records are also available, given the correlation between self-reported antisocial behavior and official arrest records (Brame, Fagan, Piquero, Schubert, and Steinberg 2004) and given the tendency of official records to under-represent the true extent of offending behavior [15], we chose to focus on these self-reported acts. In addition, because we were interested in mental health and victimization, self-report assessments were considered appropriate because research has shown that children are better at reporting internalizing symptomatology (De Los Reyes and Kazdin, 2005). Second, although this study employed one of the largest samples, to date, of serious female offenders, it is still a relatively small sample 
for analytical purposes. Trajectory analyses were possible, but we were unable to conduct other types of analyses on the predictors of trajectories. Nevertheless, our current analytic strategy still provided some important insights into the persistence vs. desistance of female offending. Finally, as our sample does not extend beyond age 25, we are unable to determine whether there is an adult-onset group of offenders. Although it has been suggested that adult onset of offending is extremely rare [42], more recent research suggests that women may have a later onset than men $[2,13]$. As such, longer follow-ups of women are needed to determine the trajectories of female offending.

Overall, the findings of this study indicate that there is, indeed, heterogeneity even among what is considered a "homogeneous" group of serious female offenders. There is a variety of different pathways that female offenders follow, and while these pathways may be similar to those followed by male offenders, the underlying psychological and environmental factors that distinguish among these trajectories are often different for females than for males. As such, there is great need for a more nuanced understanding of the most common precursors to persistent female offending. Understanding these pathways will allow for more effective design, assignment, and performance of interventions that target the specific underlying factors likely to affect long-term outcomes. Only by understanding the unique developmental pathways that lead females to serious offending can we begin to design effective prevention and intervention efforts.

\section{References}

1. Andersson, F., Levander, S., Svensson, R., \& Levander, M. T. (2012). Sex differences in offending trajectories in a Swedish cohort. Criminal Behaviour and Mental Health, 22, 108121. doi:10.1002/cbm.1822.

2. Block, C., Blokland, A., van der Werff, C., van Os, R., \& Nieuwbeerta, P. (2010). Long-term patterns of offending in women. Feminist Criminology, 5, 73-107.

3. Blokland, A., \& van Os, R. (2010). Life span offending trajectories of convicted Dutch women. International Criminal Justice Review, 20(2), 169-187. doi:10.1177/1057567710368938.

4. Cauffman, E. (2008). Juvenile offenders: risk factors. In B. Cutler (Ed.), Encyclopedia of psychology and law. Thousand Oaks: Sage.

5. Cauffman, E. (2008). Understanding the female offender. The Future of Children, 18(2), 119-142. doi:10. 1353/foc. 0.0015 .

6. Cauffman, E., Feldman, S. S., Waterman, J., \& Steiner, H. (1998). Posttraumatic stress disorder among female juvenile offenders. Journal of the American Academy of Child \& Adolescent Psychiatry, 37(11), 1209-1216. doi:10.1097/00004583-199811000-00022.

7. Chesney-Lind, M., \& Pasko, L. (2004). The female offender: girls, women, and crime. Thousand Oaks: Sage.

8. Clinkinbeard, S. S. (2014). What lies ahead: an exploration of future orientation, self-control, and delinquency. Criminal Justice Review, 39(1), 19-36. doi:10.1177/0734016813501193.

9. Conger, R., Ge, X., Elder, G., Jr., Lorenz, F., \& Simons, R. (1994). Economic stress, coercive family process, and developmental problems of adolescents. Child Development, 65, 541-561.

10. Danner, T. A., Blout, W. R., Silverman, I. J., \& Vega, M. (1995). The female chronic offender: exploring life contingency and offense history dimensions for incarcerated female offenders. Women \& Criminal Justice, 6(2), 45-66.

11. DeLisi, M. (2002). Not just a boy's club: an empirical assessment of female career criminals. Women \& Criminal Justice, 13, 27-45.

12. D’Unger, A. V., Land, K. C., \& McCall, P. L. (2002). Sex differences in age patterns of delinquent/ criminal careers: results from Poisson latent class analyses of the Philadelphia Cohort Study. Journal of Quantitative Criminology, 18(4), 349-375.

13. Eggleston, E., \& Laub, J. (2002). The onset of adult offending: a neglected dimension of the criminal career. Journal of Criminal Justice, 30, 603-622. 
14. Elliott, D. S., \& Menard, S. (1996). Delinquent friends and delinquent behavior: temporal and developmental patterns. In J. D. Hawkins (Ed.), Delinquency and crime: current theories (pp. 28-67). New York: Cambridge University Press.

15. Farrington, D. P., Jolliffe, D., Hawkins, J. D., Catalano, R. F., Hill, K. G., \& Kosterman, R. (2003). Comparing delinquency careers in court records and self-reports. Criminology, 41(3), 933-958. doi:10. 1111/j.1745-9125.2003.tb01009.x.

16. Federal Bureau of Investigation. (2013). Crime in the United States 2013. Washington, DC: U.S. Department of Justice.

17. Fontaine, N., Carbonneau, R., Vitaro, F., Barker, E. D., \& Tremblay, R. E. (2009). Research review: a critical review of studies on the developmental trajectories of antisocial behavior in females. Journal of Child Psychology and Psychiatry, 50(4), 363-385. doi:10.1111/j.1469-7610.2008.01949.x.

18. Forth, A., Kosson, D., \& Hare, R. (2003). The hare psychopathy checklist: Youth version, technical manual. New York: Multi-Health Systems Inc.

19. Giordano, P., Cernkovich, S., \& Rudolph, J. (2002). Gender, crime, and desistance: toward a theory of cognitive transformation. American Journal of Sociology, 107, 990-1064.

20. Goldweber, A., Broidy, L. M., \& Cauffman, E. (2009). Interdisciplinary perspectives on persistent female offending: a review of theory and research. In J. Savage (Ed.), The development of persistent criminality (pp. 205-230). New York: Oxford University Press, Inc.

21. Graham, J. W., Olchowski, A. E., \& Gilreath, T. D. (2007). How many imputations are really needed? Some practical clarifications of multiple imputation theory. Prevention Science, 8(3), 206-213. doi:10. 1007/s11121-007-0070-9.

22. Gunnison, E., \& McCartan, L. M. (2010). Persistent versus late onset among female offenders: a test of state dependent and population heterogeneity interpretations. Western Criminology Review, 11(3), 45-62.

23. Haynie, D. L., Giordano, P. C., Manning, W. D., \& Longmore, M. A. (2005). Adolescent romantic relationships and delinquency involvement. Criminology, 43(1), 177-210. doi:10.1111/j.0011-1348.2005. 00006.x.

24. Hennessey, M., Ford, J. D., Mahoney, K., Ko, S. J., \& Siegfried, C. B. (2004). Trauma among girls in the juvenile justice system. Los Angeles: National Child Traumatic Stress Network.

25. Herrera, V. M., \& McCloskey, L. A. (2001). Gender differences in the risk for delinquency among youth exposed to family violence. Child Abuse \& Neglect, 25(8), 1037-1051. doi:10.1016/S0145-2134(01) 00255-1.

26. Hindelang, M. J., Hirschi, T., \& Weis, J. G. (1981). Measuring delinquency. Beverly Hills: Sage.

27. Hirschi, T., \& Gottfredson, M. R. (1983). Age and the explanation of crime. American Journal of Sociology, 89, 552-584.

28. Huizinga, D., Esbensen, F., \& Weihar, A. (1991). Are there multiple paths to delinquency? Journal of Criminal Law and Criminology, 82, 83-118.

29. Jennings, W. G., Maldonado-Molina, M. M., Piquero, A. R., Odgers, C. L., Bird, H., \& Canino, G. (2010). Sex differences in trajectories of offending among Puerto Rican youth. Crime \& Delinquency, 56(3), 327-357. doi:10.1177/0011128710372478.

30. Jones, B., Nagin, D., \& Roeder, K. (2001). A SAS procedure based on mixture models for estimating developmental trajectories. Sociological Methods and Research, 29, 374-393. doi:10.1177/ 0049124101029003005.

31. Kerig, P. K., Ward, R. M., Vanderzee, K. L., \& Moeddel, M. A. (2009). Posttraumatic stress as a mediator of the relationship between trauma and mental health problems among juvenile delinquents. Journal of Youth and Adolescence, 38, 1214-1225. doi:10.1007/s10964-00809332-5.

32. Kerig, P. K., \& Becker, S. P. (2012). Trauma and girls' delinquency. In S. Miller, L. D. Leve, \& P. K. Kerig (Eds.), Delinquent girls: contexts, relationships, and adaptations (pp. 119-143). New York: Springer. doi: 10.1007/978-1-4614-0415-6 8.

33. Lambert, D. (1992). Zero inflated poisson regression with an application to defects in manufacturing. Technometrics, 34, 1-13.

34. Landsheer, J. A., \& van Dijkum, C. (2005). Male and female delinquency trajectories from pre through middle adolescence and their continuation in late adolescence. Adolescence, 40(160), 729-748.

35. Laub, J., \& Sampson, J. (2001). Understanding desistance from crime. Crime and Justice, 28, 1-69.

36. Loeber, R., Wung, P., Keenan, K., Giroux, B., Stouthamer-Loeber, M., Van Kammen, W. B., \& Maugham, B. (1993). Developmental pathways in disruptive child behavior. Development and Psychopathology, 5(1-2), 103-133. doi:10.1017/S0954579400003296.

37. Mallett, C. A. (2014). Youthful offending and delinquency: the comorbid impact of maltreatment, mental health problems, and learning disabilities. Child and Adolescent Social Work Journal, 31(4), 369-392. doi:10.1007/s10560-013-0323-3. 
38. Miller, S., Malone, P. S., Dodge, K. A., \& Conduct Problems Prevention Research Group. (2010). Developmental trajectories of boys' and girls' delinquency: differences and links to later adolescent outcomes. Journal of Abnormal Child Psychology, 38(7), 1021-1032. doi:10.1007/s10802-010-9430-1.

39. Moffitt, T. E. (1993). Adolescence-limited and life-course-persistent antisocial behavior: a developmental taxonomy. Psychological Review, 100(4), 674-701. doi:10.1037/0033-295X.100.4.674.

40. Moffitt, T. E. (1994). Natural histories of delinquency. In E. Wietekamp \& H. J. Kerner (Eds.), Crossnational longitudinal research on human development and criminal behavior (pp. 3-61). Dordrecht: Kluwer/Academic Press.

41. Moffitt, T. E. (2006). Life-course-persistent and adolescent limited antisocial behavior. In D. Cicchetti \& D. J. Cohen (Eds.), Developmental psychopathology: vol. 3. Risk, disorder, and adaptation (pp. 570-598). New York: Wiley.

42. Moffitt, T. E., Caspi, A., Rutter, M., \& Silva, P. (2001). Sex differences in antisocial behavior: conduct disorder, delinquency, and violence in the Dunedin longitudinal study. Cambridge: Cambridge University Press.

43. Monahan, K., Dmitrieva, J., \& Cauffman, E. (2014). Bad romance: gender differences in the longitudinal association between romantic relationships and deviant behavior. Journal of Research on Adolescence, 24, 12-26.

44. Monahan, K. C., Steinberg, L., Cauffman, E., \& Mulvey, E. P. (2009). Trajectories of antisocial behavior and psychosocial maturity from adolescence to young adulthood. Developmental Psychology, 45(6), 1654-1668. doi:10.1037/a0015862.

45. Monahan, K., Steinberg, L., Cauffman, E., \& Mulvey, E. (2013). Psychosocial (im)maturity from adolescence to early adulthood: distinguishing between adolescence-limited and persisting antisocial behavior. Development \& Psychopathology, 25, 1093-1105.

46. Mulvey, E., Steinberg, L., Piquero, A., Besana, M., Fagan, J., Schubert, C., \& Cauffman, E. (2010). Trajectories of desistance and continuity in antisocial behavior following court adjudication among serious adolescent offenders. Development \& Psychopathology, 22, 453-475.

47. Mulvey, E. P., Steinberg, L., Fagan, J., Cauffman, E., Piquero, A. R., Chassin, G. P., Brame, R., Schubert, C. A., Hecker, T., \& Losoya, S. H. (2004). Theory and research on desistance from antisocial activity among serious adolescent offenders. Youth Violence and Juvenile Justice, 2, 213-236. doi:10.1177/ 1541204004265864.

48. Nagin, D. S. (2005). Group-based modeling of development. Cambridge: Harvard University Press.

49. Nagin, D., \& Land, K. (1993). Age, criminal careers, and population heterogeneity: specification and estimation of a nonparametric, mixed Poisson model. Criminology, 31, 327-362.

50. Nofziger, S., \& Kurtz, D. (2005). A lifestyle model linking exposure to violence to juvenile violent offending. Journal of Research in Crime and Delinquency, 42(1), 3-26. doi:10.1177/0022427803262061.

51. Odgers, C. L., Moffitt, T. E., Broadbent, J. M., Dickson, N., Hancox, R. J., Harrington, H., \& Caspi, A. (2008). Female and male antisocial trajectories: from childhood origins to adult outcomes. Development and Psychopathology, 20(2), 673-716. doi:10.1017/S0954579408000333.

52. Piquero, A. R., Blumstein, A., Brame, R., Haapanen, R., Mulvey, E. P., \& Nagin, D. S. (2001). Assessing the impact of exposure time and incapacitation on longitudinal trajectories of criminal offending. Journal of Adolescent Research, 16, 54-74. doi:10.1177/0743558401161005.

53. Piquero, A. R., Farrington, D. P., \& Blumstein, A. (2003). The criminal career paradigm. In M. Tonry (Ed.), Crime and justice: a review of research (Vol. 30, pp. 359-506). Chicago: University of Chicago Press.

54. Piquero, A. (2008). Taking stock of developmental trajectories of criminal activity over the life course. In A. M. Liberman (Ed.), The long view of crime: a synthesis of longitudinal research (pp. 23-78). New York: Springer. doi:10.1007/978-0-387-71165-2_2.

55. Puzzanchera, C. (2009). Juvenile arrests 2008. Washington, DC: Office of Juvenile Justice and Delinquency Prevention.

56. Reitan, R. (1979). Trail-making test. Arizona: Reitan Neuropsychology Laboratory.

57. Roisman, G. I., Aguilar, B., \& Egeland, B. (2004). Antisocial behavior in the transition to adulthood: the independent and interactive roles of developmental history and emerging developmental tasks. Development and Psychopathology, 16, 857-871.

58. Roisman, G. I., Monahan, K. C., Campbell, S. B., Steinberg, L., Cauffman, E., \& The National Institute of Child Health and Human Development Early Child Care Research Network. (2010). Is adolescence-onset antisocial behavior developmentally normative? Development and Psychopathology, 22, 295-311.

59. Schubert, C. A., Mulvey, E. P., Steinberg, L., Cauffman, E., Losoya, S. H., Hecker, T., Chassin, L., \& Knight, G. P. (2004). Operational lessons from the pathways to desistance project. Youth Violence and Juvenile Justice, 2, 237-255. doi:10.1177/1541204004265875. 
60. Schwab-Stone, M. E., Ayers, T. S., Kasprow, W., Voyce, C., Barone, C., Schriver, T., \& Weissberg, R. P. (1995). No safe haven: a study of violence exposure in an urban community. Journal of the American Academy of Child and Adolescent Psychiatry, 34(10), 1343-1352.

61. Steffensmeier, D., \& Allan, E. (1996). Gender and crime: toward a gendered theory of female offending. Annual Review of Sociology, 22, 459-487. http://www.jstor.org/stable/2083439.

62. Steinberg, L., \& Cauffman, E. (1996). Maturity of judgment in adolescence: psychosocial factors in adolescent decision making. Law \& Human Behavior, 20, 249-272.

63. Steinberg, L., \& Monahan, K. (2007). Age differences in resistance to peer influence. Developmental Psychopathology, 43, 1531-1543.

64. Steinberg, L., Dornbusch, S., \& Darling, N. (1992). Impact of parenting practices on adolescent achievement. authoritative parenting, school involvement, and encouragement to succeed. Child Development, 63, 1266-1281.

65. Stolzenberg, L., \& D'Alessio, S. J. (2008). Co-offending and the age-crime curve. Journal of Research in Crime and Delinquency, 45(1), 65-86. doi:10.1177/0022427807309441.

66. Thornberry, T.P., \& Krohn, M.D. 2000. "The self-report method for measuring delinquency and crime. Pp. 33-83 in Criminal Justice 2000: Vol. 4: Measurement and Analysis of Crime and Justice, edited by D. Duffee, R.D. Crutchfield, S. Mastrofski, L. Mazerolle, and D. McDowall. National Institute of Justice/ Department of Justice.

67. Thornberry, T. P., \& Krohn, M. D. (2003). Comparison of self-report and official data for measuring crime. In J. V. Pepper \& C. V. Petrie (Eds.), Measurement problems in criminal justice research: workshop summary (pp. 43-94). Washington, DC: National Academy Press.

68. Thornberry, T. P., Lizotte, A. J., Krohn, M. D., Farnworth, M., \& Jang, S. J. (1994). Delinquent peers, beliefs, and delinquent behavior: a longitudinal test of interactional theory. Criminology, 32, 47-83.

69. Tyler, T. (1997). Procedural fairness and compliance with the law. Swiss Journal of Economics and Statistics, 133(2/2), 219-240.

70. Uggen, C., \& Kruttschnitt, C. (1998). Crime in the breaking: gender differences in desistance. Law \& Society Review, 32(2), 339-366.

71. Wechsler, D. (1999). Wechsler abbreviated scale of intelligence. The psychological corporation. New York: Harcourt Brace \& Company.

72. Weerman, F. M., \& Hoeve, M. (2012). Peers and delinquency among girls and boys: are sex differences in delinquency explained by peer factors? European Journal of Criminology, 9(3), 228-244.

73. White, N. A., \& Piquero, A. R. (2004). A preliminary empirical test of Silverthorn and Frick's delayed onset pathway in girls using an urban, African-American, US-based sample. Criminal Behavior and Mental Health, 14(4), 291-309. doi:10.1002/cbm.595. 